Article

\title{
Necessity of a Multifaceted Approach in Analyzing Growth of Impervious Surfaces
}

\author{
Ghali Abdullahi Abubakar ${ }^{1}{ }^{1}$, Jiexia Wu ${ }^{2}$, Amir Reza Shahtahmassebi ${ }^{1}$ and Ke Wang ${ }^{1, *}$ \\ 1 Institute of Agricultural Remote Sensing and Information Technology, College of Environment and Natural \\ Resource, Zhejiang University, Hangzhou 310058, China; ghaliaa@zju.edu.cn (G.A.A.); \\ amir511@zju.edu.cn (A.R.S.) \\ 2 Atmospheric Department, Beijing Piesat Information Technology Co., Ltd., Beijing 100195, China; \\ wujiexia@piesat.cn \\ * Correspondence: kwang@zju.edu.cn; Tel.: +86-571-8898-2272
}

Received: 29 March 2020; Accepted: 12 May 2020; Published: 18 May 2020

\begin{abstract}
While substantial efforts have been devoted to the remote sensing of impervious surfaces, few studies have developed frameworks to connect impervious surfaces' growth with spatial planning decisions. To this end, this paper develops a multifaceted approach with three components: Visualization, numerical analysis, and simulation at the sub-pixel level. First, the growth of impervious surfaces was visualized through write function memory (WFM) insertion for the period of 1974-2009 of Cixi County in Zhejiang Province, China. Second, anomaly detection, statistical analysis, and landscape metrics were used to quantify changes in impervious surfaces over time. Finally, a slope, land use, exclusion, urban extent, transportation, and hill shade (SLEUTH) cellular automata model was employed to simulate the impervious surface growth until 2015 under four specific spatial decision scenarios: Current trends, environmental protection growth, business growth, and Chinese policy for protecting rural regions. The results show that Cixi County experienced compact growth due to expansion and internal intensification. Interestingly, the SLEUTH reveals that the projected space of impervious surfaces' growth was consistent with reality in 2015. The framework established in this study holds considerable potential for improving our understanding of the interaction between impervious surfaces' growth and planning aspects.
\end{abstract}

Keywords: impervious surface; spatial decision; cellular automata; spatial decision scenarios

\section{Introduction}

Urban regions are described as ecosystems with biotic and abiotic components, which consist of function, connection, structure, and history [1,2]. One of the key components of urban ecosystems is impervious surfaces, which consist of impermeable landscape features, including roads, buildings, parking lots, railways, and sidewalks that prevent water from infiltrating the soil [3]. Hence, the impervious surface area is strongly associated with urban land use conditions, such as the size and density of urban areas [4]. The growth of impervious surfaces is likely to lead to an array of environmental problems in cities, such as soil sealing [5], runoff [6], water pollution [7], and urban heat islands [8]. In response, there is a growing recognition of characterization of changes in impervious surfaces, such as their abundance, spatio-dynamics, and future growth $[9,10]$. This information is crucial to a range of issues in urban geography, such as sustainable land management and ecosystem conservation [11,12].

Characterizing growth of impervious surfaces raises two fundamental questions: (1) How are impervious surfaces generated? and (2) Where does such growth occur? Focusing on these questions, Shahtahmassebi et al. [13] pointed out that the growth of impervious surfaces is a function of new 
development and intensification (Figure 1). New development is related to the conversion of pervious lands into impervious surfaces, which generally occurs around urban edges, along highways and existing open spaces. Urban expansion, infilling and the carpeting phenomenon lead to the new development of impervious surfaces. Intensification reflects changes in the amount of impervious surfaces that can be observed within existing urban regions (e.g., brown fields). Intensification gives rise to the densification of urban regions. Both new development and intensification have an important role to play in spatial distribution of impervious surfaces' growth.

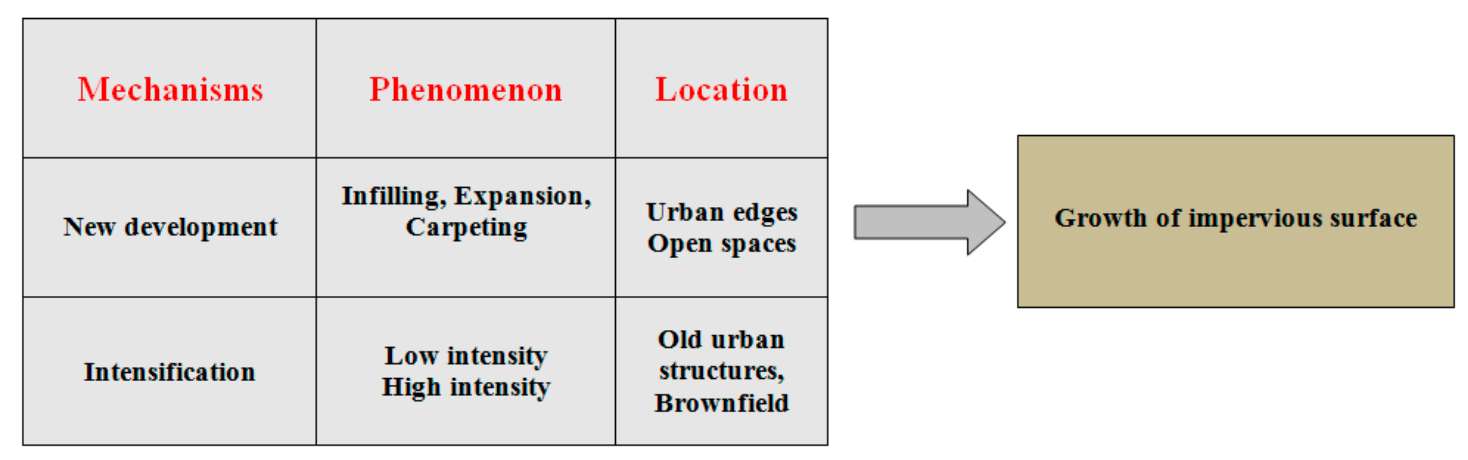

Figure 1. Hypothetical framework of impervious surfaces' growth [13].

A number of studies identified significant relationships between impervious surfaces' growth (new development and intensification) and spatial planning decision [14,15]. In this view, growth of impervious surfaces depends not just on designing concepts, but, more importantly, on how and where such surfaces are created by spatial planning decisions (e.g., land use policy [15], urban redevelopment activities [16], and industrialization [17]). Therefore, providing a framework that monitors past, current, and future growth of impervious surfaces can contribute to better implementation of spatial planning decisions.

In the past two decades, extensive research has demonstrated the utility of remotely sensed data [18] in a range of impervious surface studies, such as mapping [9], sensors [19], spatial resolution [20], and change detection [21]. Despite the substantial efforts, few studies analyzed growth of impervious surfaces from three different points of view at the same time: Visualization, numerical analysis, and simulation. Moreover, little is known about how such investigations explain change in impervious surfaces in the context of spatial planning decisions [14,17].

This study aimed to develop a multifaceted approach to connect growth of impervious surfaces with spatial planning decisions. Three key research questions were addressed in this study:

- How can we establish a reliable multifaceted approach to analyze the changes in impervious surfaces?

- How do spatial development decisions impact distribution of impervious surfaces' growth?

- Is simulated impervious surface growth consistent with reality?

\section{Materials and Methods}

\subsection{Study Area}

This study was set in Cixi County in Zhejiang province, China. This county is located along the coast of eastern Zhejiang Province, on the south bank of Hangzhou Bay (Figure 2). Cixi County covers a total area of 1154 square kilometers, with about 1.02 million registered permanent residents [17]. Cixi County ranked third among the top 100 medium-sized counties in China in 2007 with respect to the economic performance [17]. Cixi County's Gross Domestic Product (GDP) rose from 15 billion RMB in 1987 to 62.6 billion RMB in 2009 [17]. Moreover, it is located between three mega-cities: Shanghai, 
Hangzhou, and Ningbo. Since the opening of the Hangzhou Bay Bridge to Cixi in 2009, this county has become an important industrial zone for domestic and international activities.

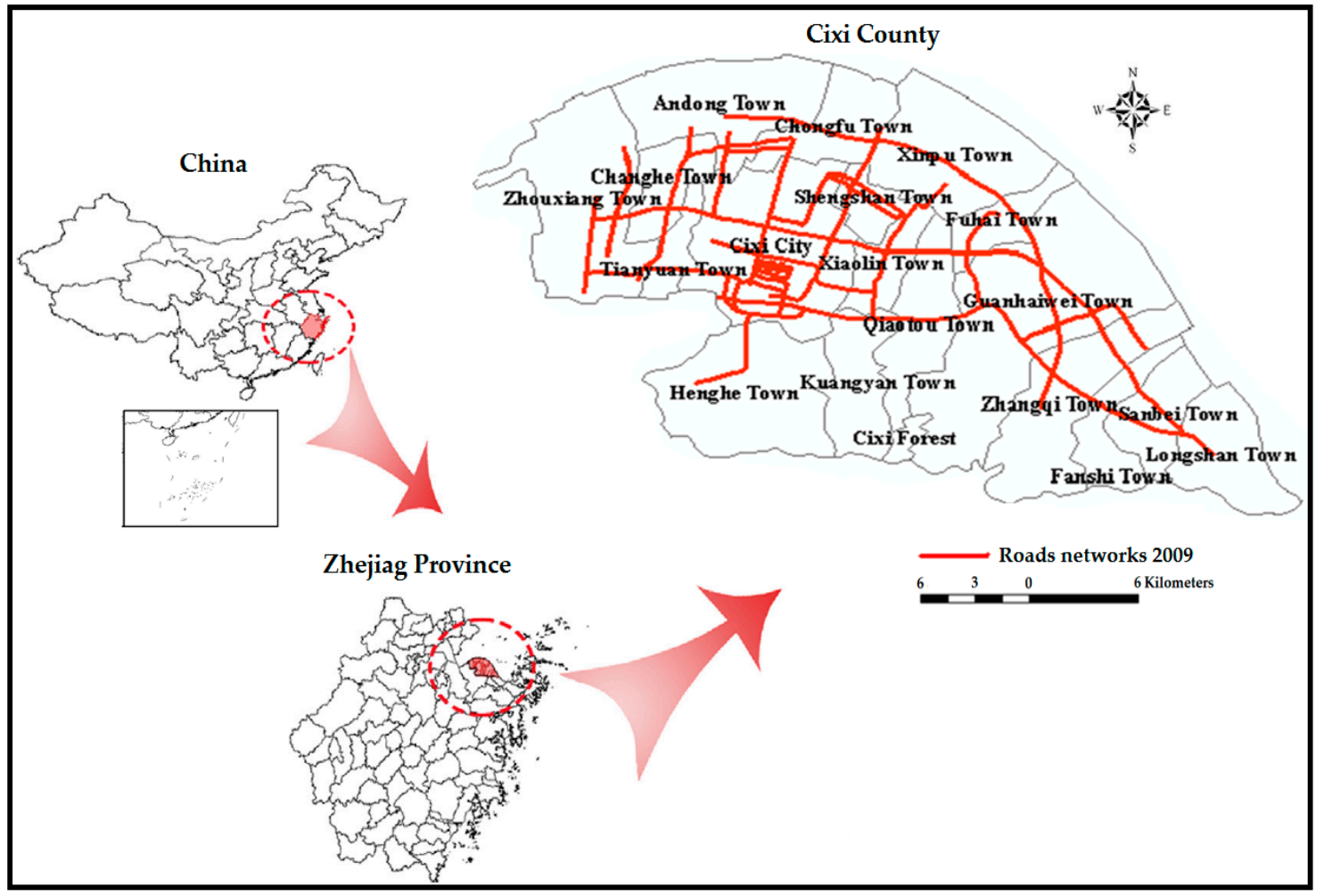

Figure 2. Study area.

\subsection{Impervious Surface Data}

Continuous digital impervious surface data of 1974, 1981, 1987, 1995, 2000, 2002, and 2009 were used in this study to analyze the growth of impervious surfaces [22] (Table 1). The impervious surface data with $30 \mathrm{~m}$ pixel size were obtained from the previous project by Shahtahmassebi et al. [22]. These data were generated using Multiple Endmember Spectral Mixture (MESMA) in ENVI RSI 5.1 (please see Supplementary Material, Sections S1-S4).

Table 1. Summary of basic properties of the satellite imagery used [22].

\begin{tabular}{ccc}
\hline Date & Type of Image * $^{*}$ & Spatial Resolution (m) \\
\hline 13 Feb 1974 & Landsat 1MSS $^{1}$ & 30 (resampled) \\
15 July 1981 & Landsat 3MSS & 30 (resampled) \\
18 May 1987 & TM $^{2}$ 5 & 30 \\
13 September 1995 & TM 5 $^{3}$ & 30 \\
14 June 2000 & ETM $^{3}$ 7 & 30 \\
11 November 2002 & ETM+ 7 & 30 \\
10 October 2009 & TM 5 & 30
\end{tabular}

${ }^{1}$ Multispectral Scanner; ${ }^{2}$ Thematic Mapper; ${ }^{3}$ Enhanced Thematic Mapper Plus; * Thermal (TM and ETM+) bands were excluded from the analysis.

\subsection{Research Frameworkfor Monitoring Growth of Impervious Surfaces: A Multifaceted Approach}

In the context of spatial planning decisions, we need to establish approaches to understand the interaction between impervious surface growths and the planning aspects. Therefore, such approaches should integrate measurements of dynamics (monitor growth) into planning/policies and simulation 
of mechanisms of growth through existing or hypothetical planning scenarios. To achieve this aim, we proposed a multifaceted framework, which includes three major steps (Figure 3):

(1) Visual interpretation: We adopted a method to visualize growth of impervious surfaces.

(2) Numerical analysis: Growth of impervious surfaces was examined through anomaly detection, statistical analysis, and landscape metrics.

(3) Simulation: Behaviors of impervious surface growth were modeled using the slope, land use, exclusion, urban extent, transportation, and hill shade (SLEUTH) model.

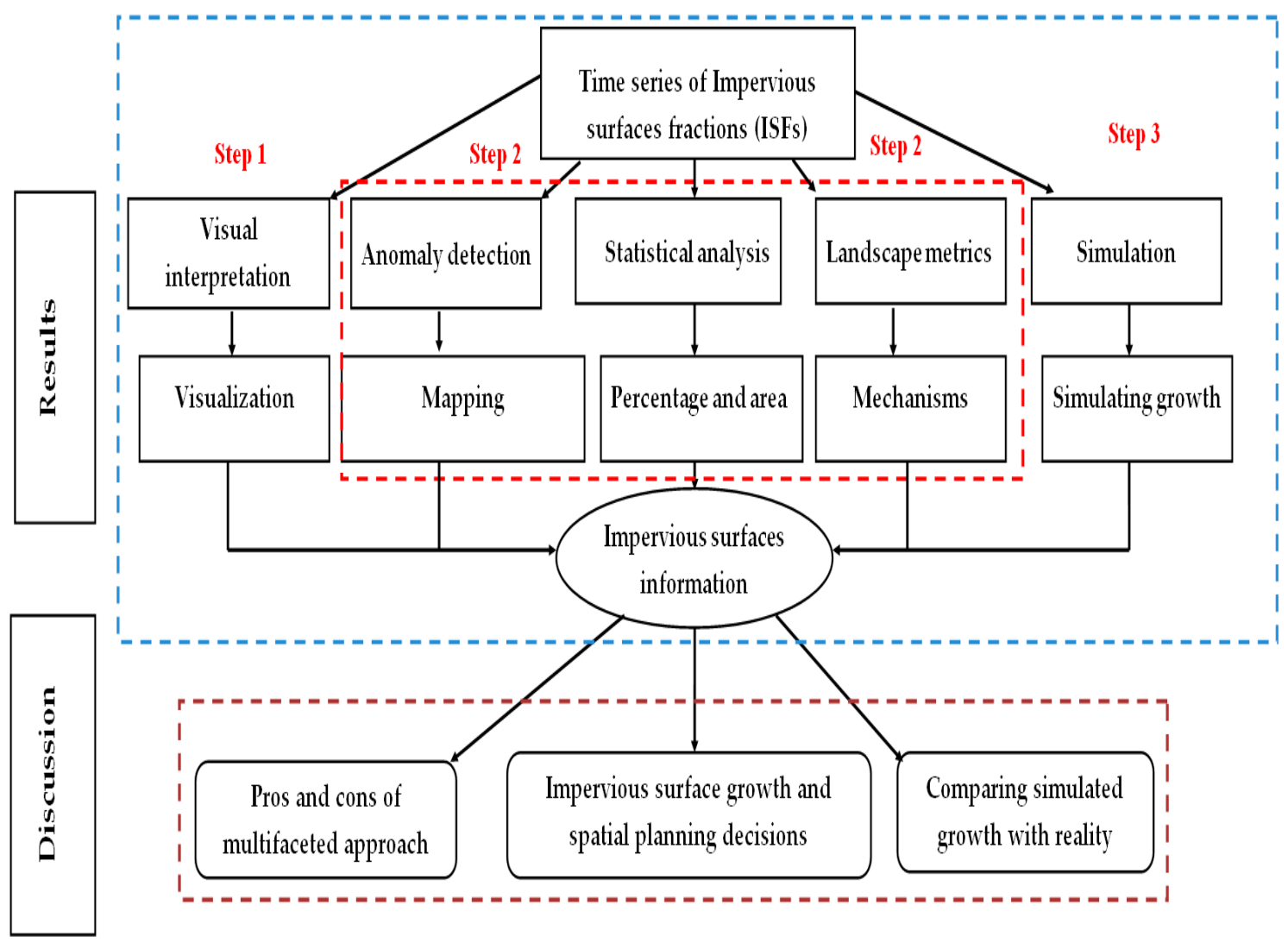

Figure 3. Analytical workflow based on the multifaceted approach.

The outcomes of these steps are presented in the results section. The discussion section explains the results with respect to the research questions developed in the introduction (Section 1).

\subsubsection{Visualization}

A simple yet efficient approach of visual change detection is write function memory (WFM). In effect, each band (or processed product) from time series data may be placed into each of the three WFM bands (Red-Green-Blue (RGB)) to detect changes in the imagery [23]. Previous studies showed that by knowing the date of an impervious surface image along with the corresponding bands, the colors can be interpreted to detect changes in impervious surfaces [22,24]. Accordingly with these studies, individual bands from multiple impervious surface dates were inserted into each of the three WFM banks (RGB) to highlight changes in impervious surfaces.

\subsubsection{Numerical Analysis}

In order to comprehensively assess the changes in impervious surfaces, we used two methods: Residual regression and landscape metrics. Residual regression was employed to identify the locations 
of intensification and the new development of impervious surfaces. The residual regression, proposed by Shahtahamssebi et al. [25], refers to change at the sub-pixel level, which derives from a linear regression model between target dates and other dates (please see [25] for theoretical details). The derived results are then subjected to Getis_Ord (Gi) spatial statistics to detect hotspot regions [17,25]. In this technique, intensification is negative or positive due to the changes within existing impervious surfaces. However, new developments of impervious surfaces have positive values due to the sharp conversion of pervious lands into impervious surfaces.

Six landscape pattern metrics were selected to quantify mechanisms of impervious surface growth (Table 2). These landscape metrics were calculated by Fragstates 3.3 [26]. First, all values less than 0.0 and greater than 1.0 were removed from each impervious surface image. Then, all impervious pixels between 0.2 and 1.0 were classified as impervious cover class. Selecting this range was based on a previous study in Cixi County [17].

Table 2. Spatial metrics selected in this study [26].

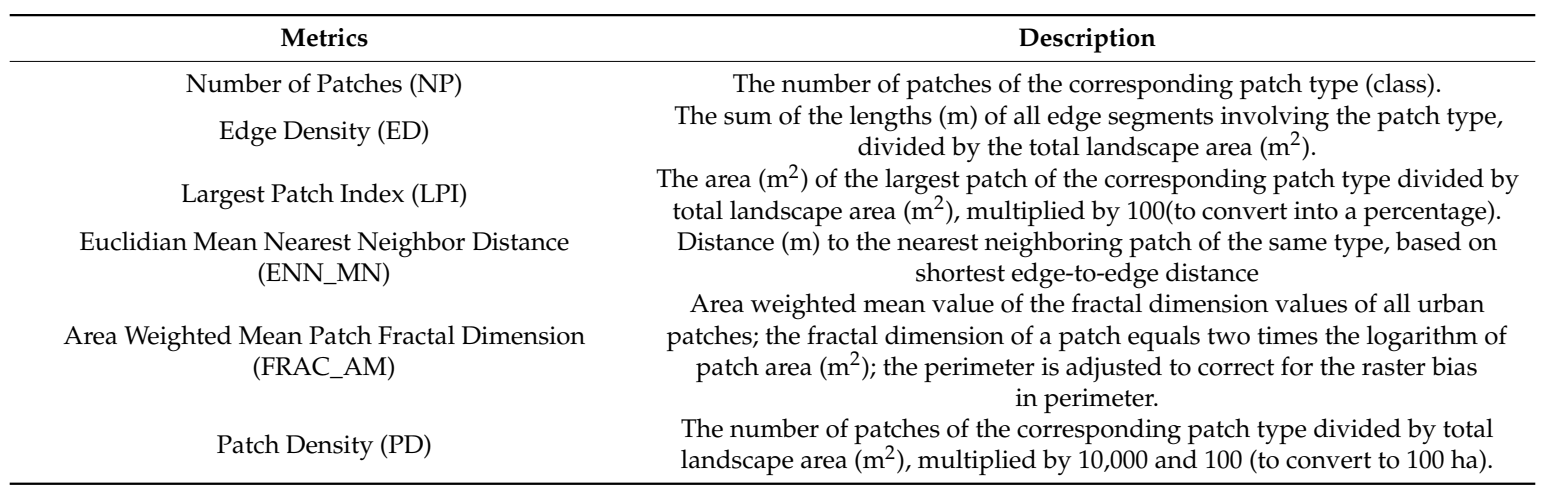

\subsubsection{Simulations}

The SLEUTH model is a cellular-automata-based computer simulation model for simulating urban growth and land use/land cover change (LULCC) [27]. SLEUTH, which was proposed by Clarke et al. in [28], refers to an acronym for the input data requirements for running the simulation: Slope, land use, exclusion, urban extent, transportation, and hill shade. This model is able to capture the complex emergence of urban growth due to its rules and calibration procedures [29-31]. Furthermore, the SLEUTH model can insert urban development policies and plans into the models through variations in the excluded layer [32,33]. SLEUTH simulates dynamic urban growth based on four rules: Spontaneous growth, new spreading center, edge growth, and road influence [34]. These rules are controlled by five growth coefficients: Diffusion, breed, spread, road gravity, and slope resistance. The description of the SLEUTH rules and coefficients can be found in Jantz et al. [35]. In SLEUTH, the calibration process begins with coarse spatial resolution and ends with high spatial resolution. During this process, users select appropriate values of five urban growth factors that control behaviors of the system.

Impervious surface growth in Cixi County was simulated for the period 1974-2009 by using four specific spatial decision scenarios (Figure 4) [22]:

1. Current trends (CT), which mirrored policies that existed in Cixi County.

2. Environmental protection growth (EPG), which reflected strict protection of present agricultural land in Cixi County during the next seven years. According to this scenario, new urban development would be prohibited around urban regions and along highways.

3. Business growth (BG), which assumed an increase in demand for land for residential and business activities, in which agricultural land would be affected by urban activities with $20 \%$ probability.

4. Chinese policy for protecting rural regions (CPPR), which considered that all rural lands have been protected from urban development. In addition, some old rural lands were converted into cultivated lands; therefore, farmers had to move to new settlement regions. In the CPPR scenario, 
we considered that there was $80 \%$ probability of urbanization in side rural regions (infill growth) and $90 \%$ around them (outward growth).
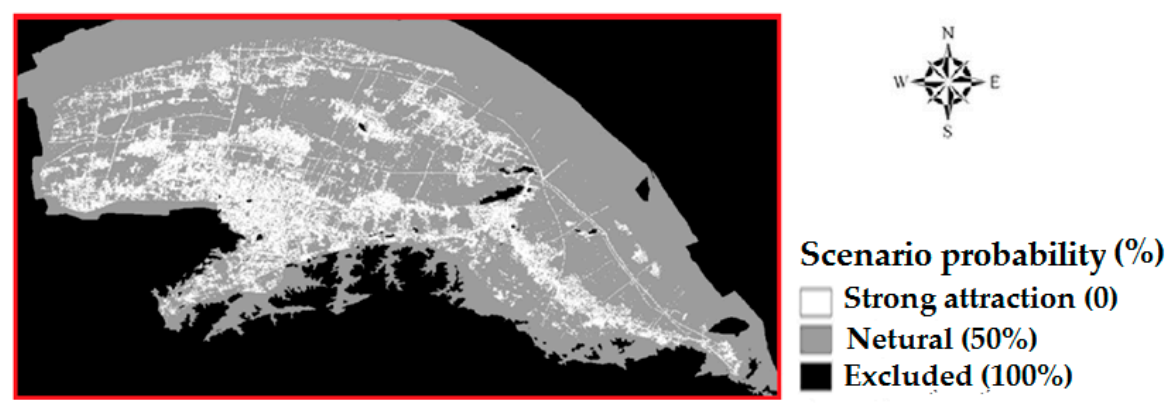

(a)

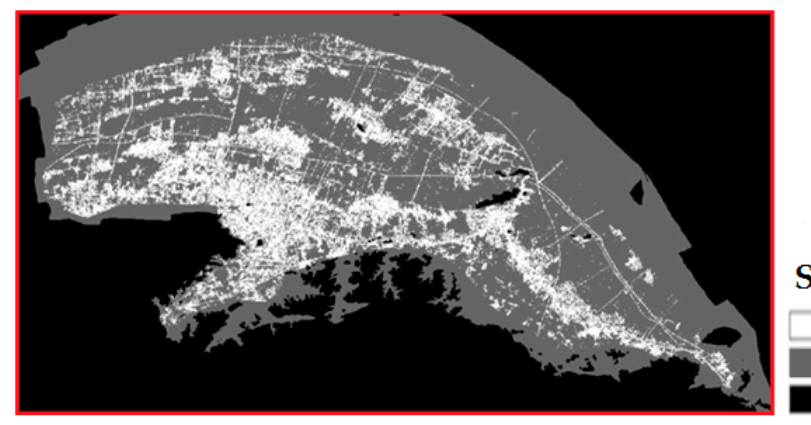

Scenario probability $(\%)$

$\square$ Strong attraction (0)

Strong protection $(70 \%)$

Excluded (100\%)

(b)

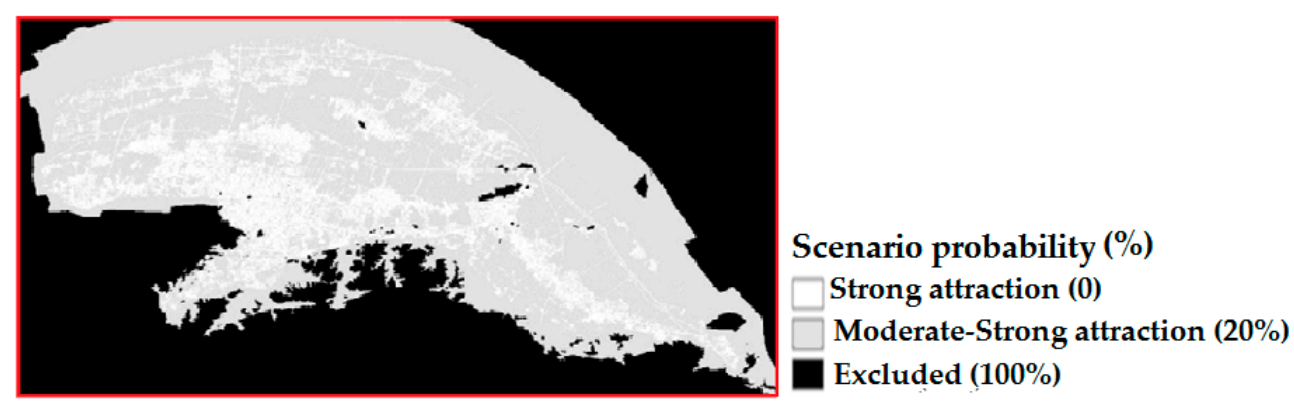

(c)

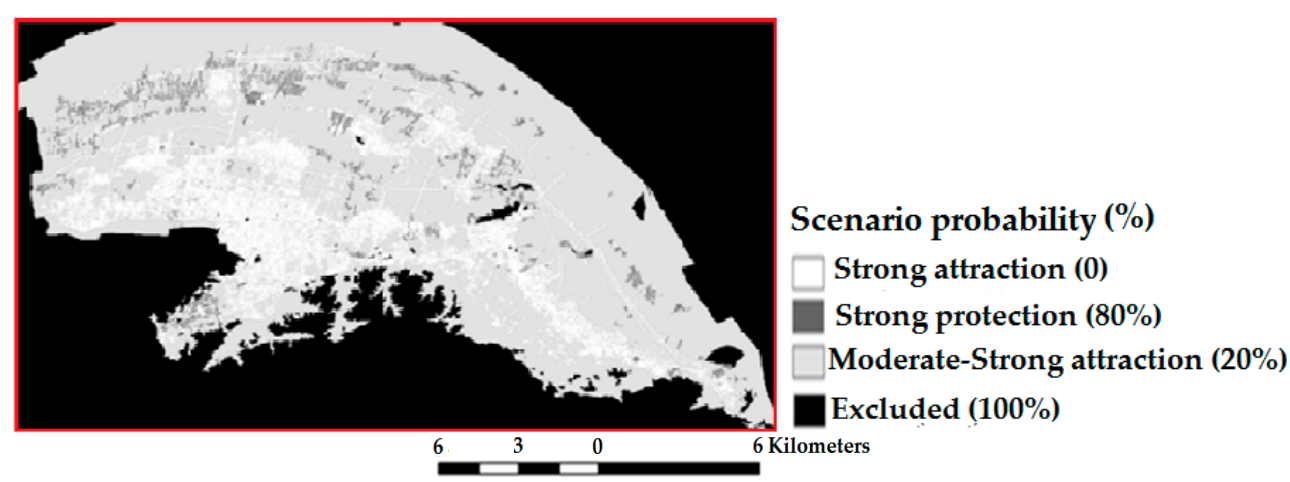

Figure 4. Spatial decision scenarios of Cixi County for slope, land use, exclusion, urban extent, transportation, and hill shade (SLEUTH): (a) current trends (CT), (b) environmental protection growth (EPG), (c) business growth (BG), and (d) Chinese policy for protecting rural regions (CPPR). 
It is noteworthy that Cixi County's spatial development planning for 2002-2020 was the main source for designing the CT, EPG, and BG scenarios (please see Supplementary Material-Section S5). Accordingly, this map was used to delineate development-prone regions and estimate corresponding weights on a range from 0 to 100, in which 0 indicates highly attractive regions, 50 is neutral, and 100 reflects areas excluded from development. Moreover, the Basic Farm Protection Policy in 1994 was employed to establish the CPPR scenario [36]. The main aim of this policy was to protect conversion of farmlands for nonagricultural activities.

Finally, SLEUTH was fed with the following layers: Slope, time series of impervious surfaces (1974-2009), Exclusion (scenario layers), Urban Extent, Transportation, and Hillshade [22].

\section{Results}

\subsection{Visualization}

The construction of the RGB impervious surface (RGB_IS) images provided intelligent and informative information on changes in impervious surfaces. For instance, RGB_IS No.1 (Figure 5a) shows that impervious surface growth took place in urban centers, while small portions of this growth occurred in the urban fringe. In this respect, urban centers experienced intensification or change in the proportion of impervious surfaces within the pixels. Moreover, urban peripheries and regions along transportation corridors witnessed new development of impervious surfaces (Figure 5a-green color). It is noteworthy that the initial analysis in this study showed that the amount of impervious surfaces in 1974 was low; therefore, adding this image to the RGB_IS might not reveal considerable change. Thus, we excluded these years from this section.

RGB_IS No.2 suggested a more complex pattern of impervious surface growth (Figure 6a-green color). Urban centers witnessed steady change with full maturity, while rapid growth of impervious surfaces was triggered in urban edges. Interestingly, developing suburbs caused two or more towns to connect and form large impervious surfaces. A careful comparison between RGB_IS No.1 and RGB_IS No.2 indicated that many open spaces within existing urban region were affected by impervious surface infilling procedures after 2002 in Cixi County. The visual inspection suggested that impervious surfaces' growth there shifted to compactness and the saturation stage of development.

\subsection{Numerical Analysis}

Figure 7 shows the anomalous patterns of impervious surfaces mapped by residual regression based on Getis_Ord (Gi) of Cixi County in 1995, 2002, and 2009. Our initial investigation showed that adding the 1974 and 1987 images did not reveal considerable change due to the small number of impervious surfaces; thus, we excluded these years from this section. Getis_Ord (Gi) was divided into three major categories. The first category included the highest values of Getis_Ord (Gi) $(0.07<$ (red color)), which represented anomalous regions or sprawl. This class indicated conversion of pervious surfaces into impermeable lands; urban edges, the area along the highway, and rural regions experienced this pattern. The second category was defined as a medium class that included 0.01 to 0.06 , which behaved similarly to the first category. The lowest values of Getis_Ord (Gi) were placed in the rest of the categories $(<-0.07$ to -0.01$)$. These categories were observed in urban regions and particularly urban centers that showed intensification within urban regions (i.e., changing impervious surfaces into impervious surfaces). 


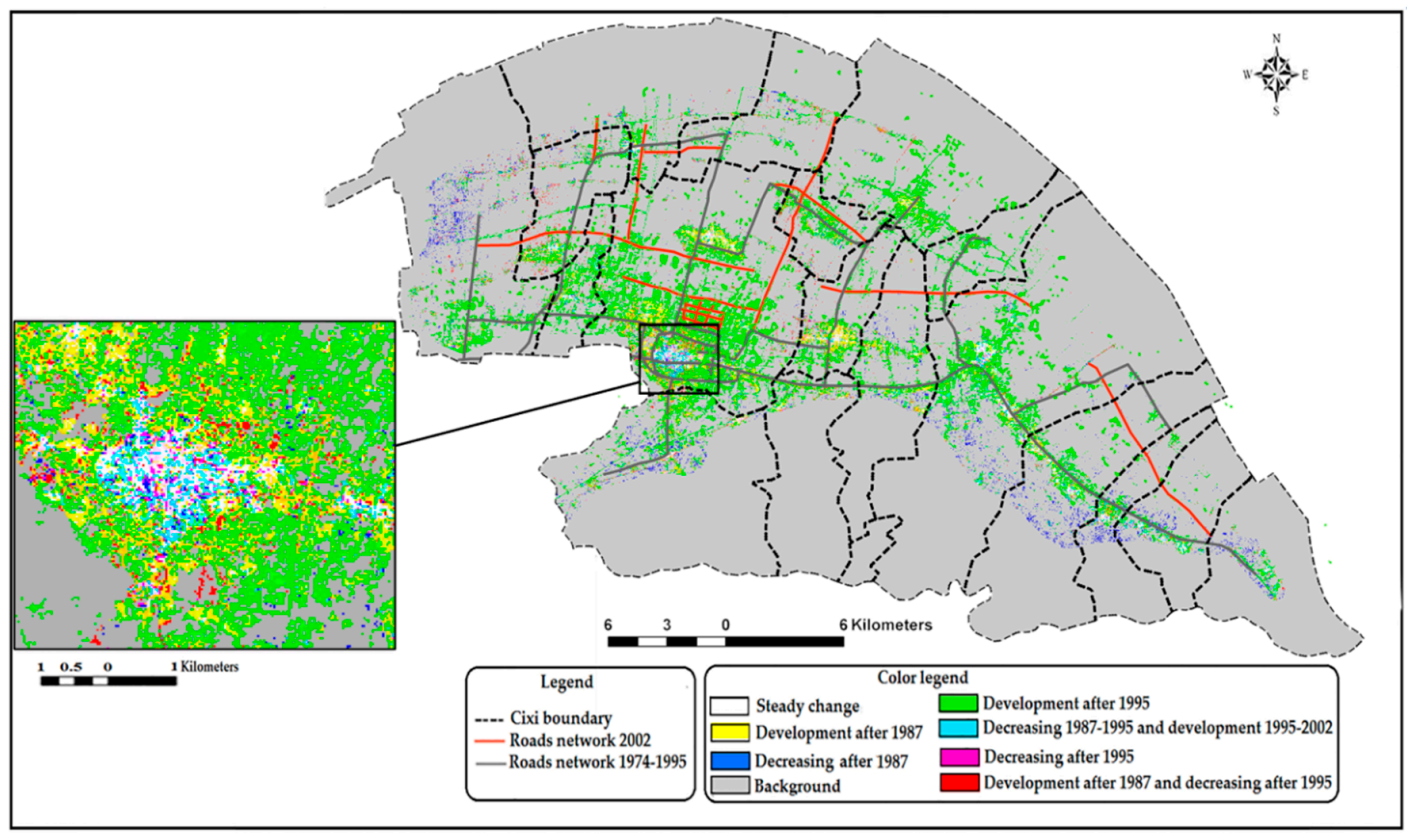

(a)

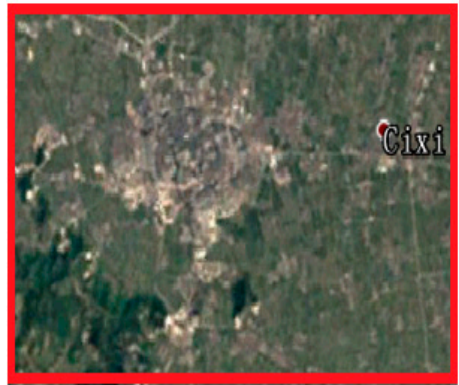

(b)
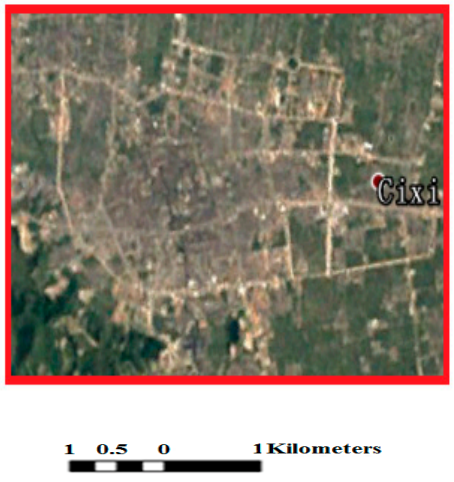

(c)

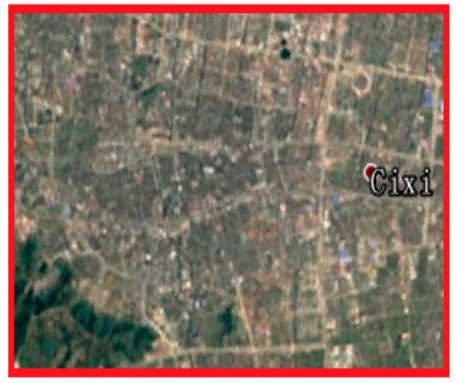

(d)

Figure 5. (a) Red-green-blue (RGB) impervious surface RGB_IS No.1 consists of impervious surface fractions in 1987, 1995, and 2002; corresponding zoom region (small black square): (b) Landsat 1987, (c) Landsat 1995, and (d) Landsat 2002. The Landsat images over Cixi city were obtained from Google Earth ${ }^{\mathrm{TM}}$; the coordinates of this location are ( $30^{\circ} 10^{\prime} 16.42^{\prime \prime} \mathrm{N}$ and $\left.121^{\circ} 16^{\prime} 04.24^{\prime \prime} \mathrm{E}\right)$.

\subsection{Statistical Analysis}

In 1974, the area of impervious surfaces was about 365.18 ha. However, by 2009, the impervious surface area had increased by 40 times to $16,494.75$ ha (Table 3). 
Table 3. Land use statistics in Cixi County between 1974 and 2009.

\begin{tabular}{ccc}
\hline Year & Non-Impervious Surface(ha) & Impervious Surface(ha) \\
\hline 1974 & $52,283.55$ & 365.18 \\
1981 & $51,965.28$ & 684 \\
1987 & $50,325.84$ & 2339.19 \\
1995 & $45,999.72$ & 6665.22 \\
2002 & $42,460.02$ & $10,204.92$ \\
2009 & $36,170.19$ & $16,494.75$ \\
\hline
\end{tabular}

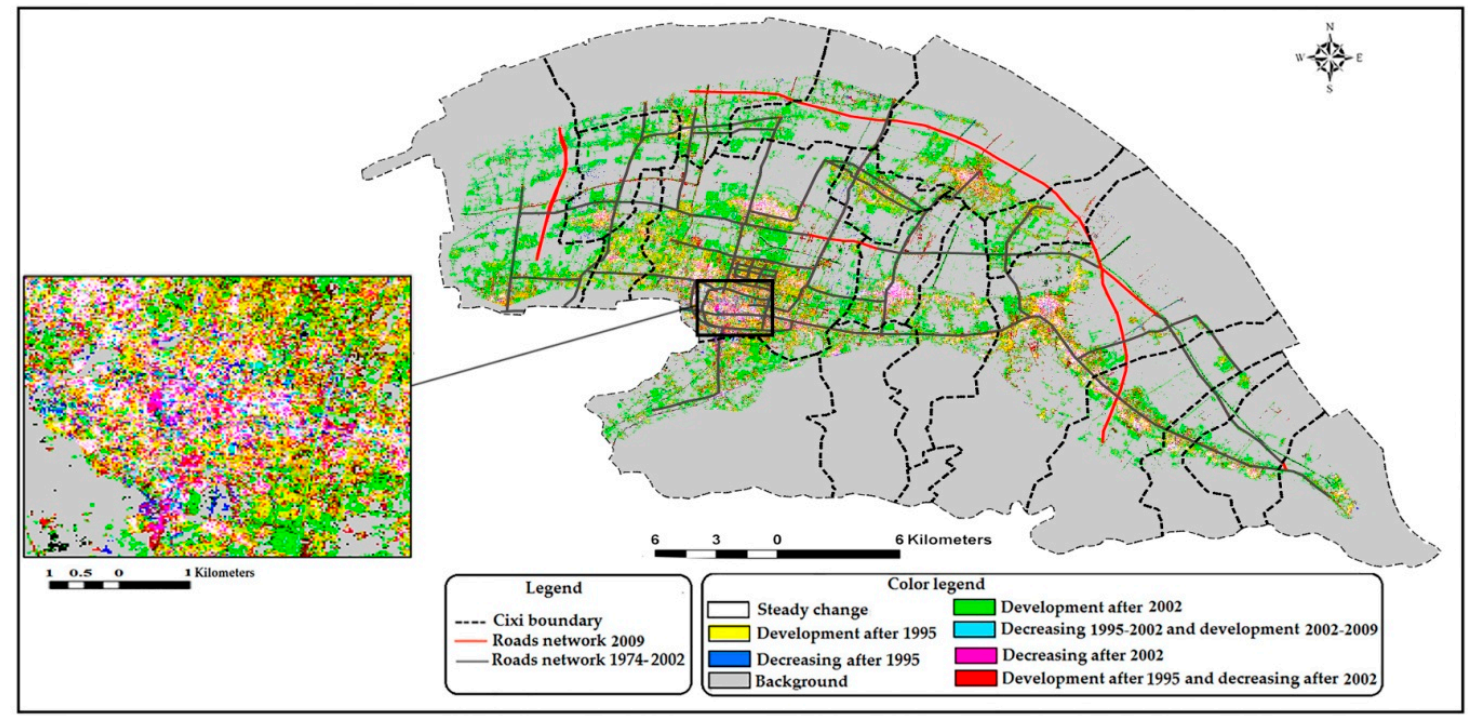

(a)

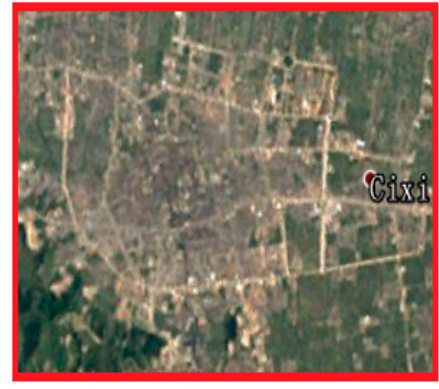

(b)
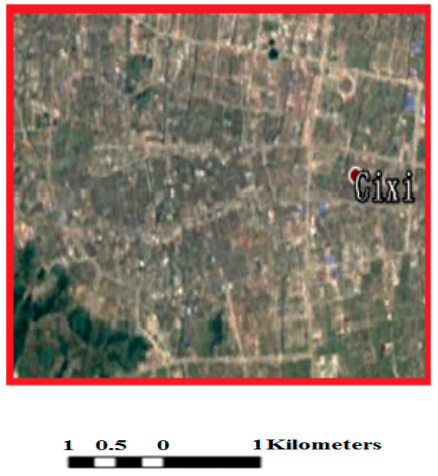

(c)

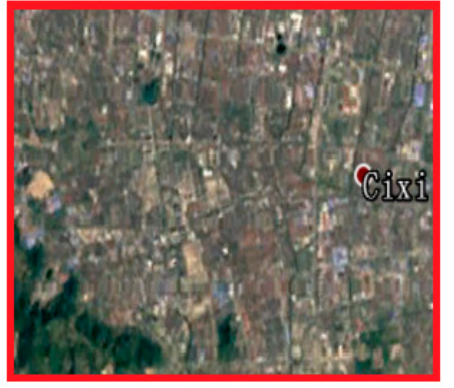

(d)

Figure 6. (a) RGB_IS No.2 consists of impervious surface fractions in 1995, 2002, and 2009; corresponding zoom region (small black square): (b) Landsat 1995, (c) Landsat 2002, and (d) Landsat 2009. The Landsat images over Cixi city were obtained from Google Earth ${ }^{\mathrm{TM}}$; the coordinates of this location are $\left(30^{\circ} 10^{\prime} 16.42^{\prime \prime} \mathrm{N}, 121^{\circ} 16^{\prime} 04.24^{\prime \prime} \mathrm{E}\right)$. 


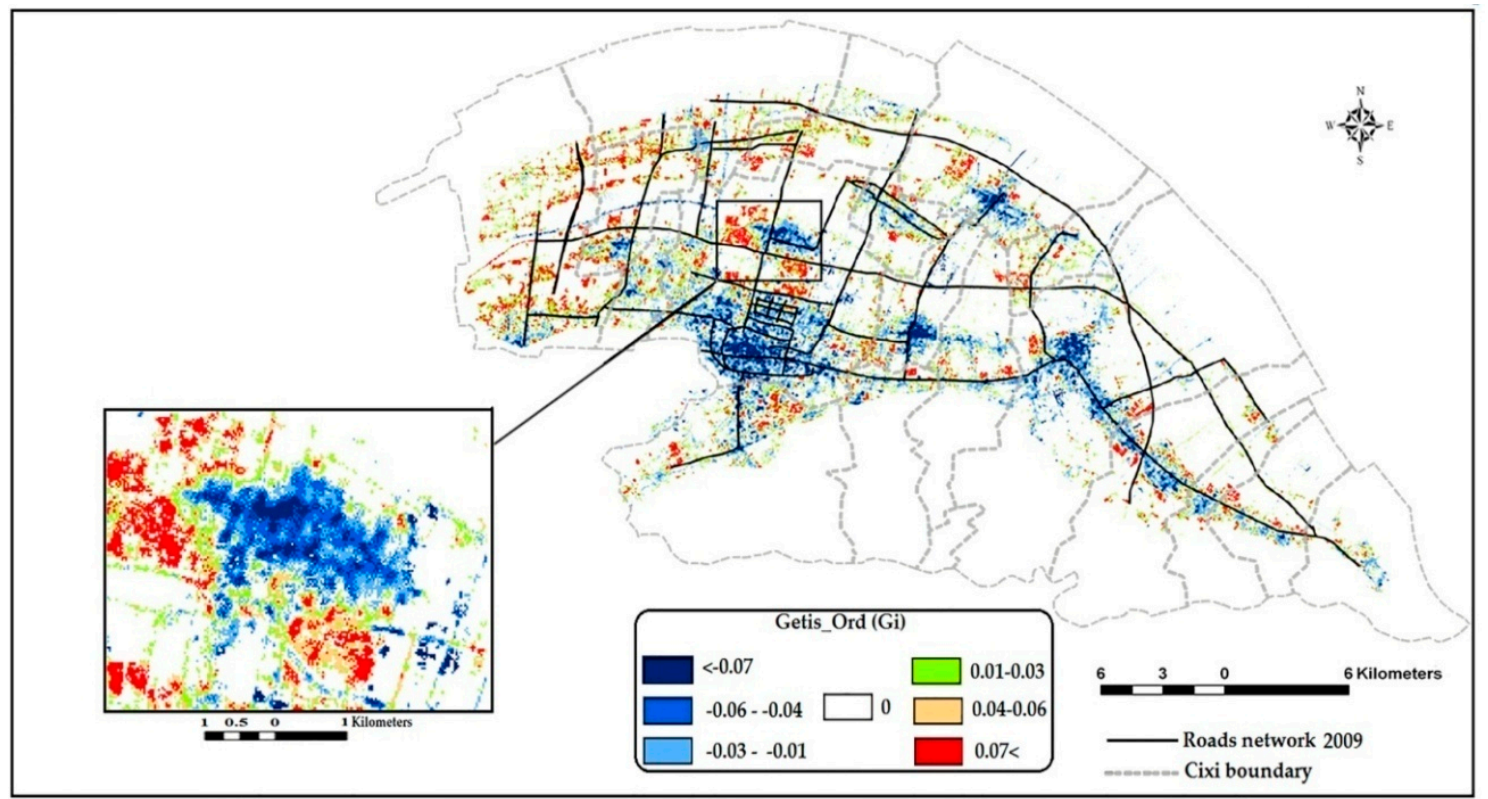

Figure 7. Summary of impervious surface changes based on the anomaly map. The zoom location is Kandun Town; the coordinates of this location are (30 $\left.13^{\prime} 36.793^{\prime \prime} \mathrm{N}, 121^{\circ} 15^{\prime} 29.002^{\prime \prime} \mathrm{E}\right)$.

Figures 8 and 9 indicate impervious surface area and imperviousness (\%) for major towns in Cixi County. The growth of impervious surfaces was observed mainly in Cixi city, Zhouxian Town, and Guanhaiwei Town. Additionally, most of the towns experienced higher amounts of imperviousness $(\%)$ in 2009 compared with the other years.

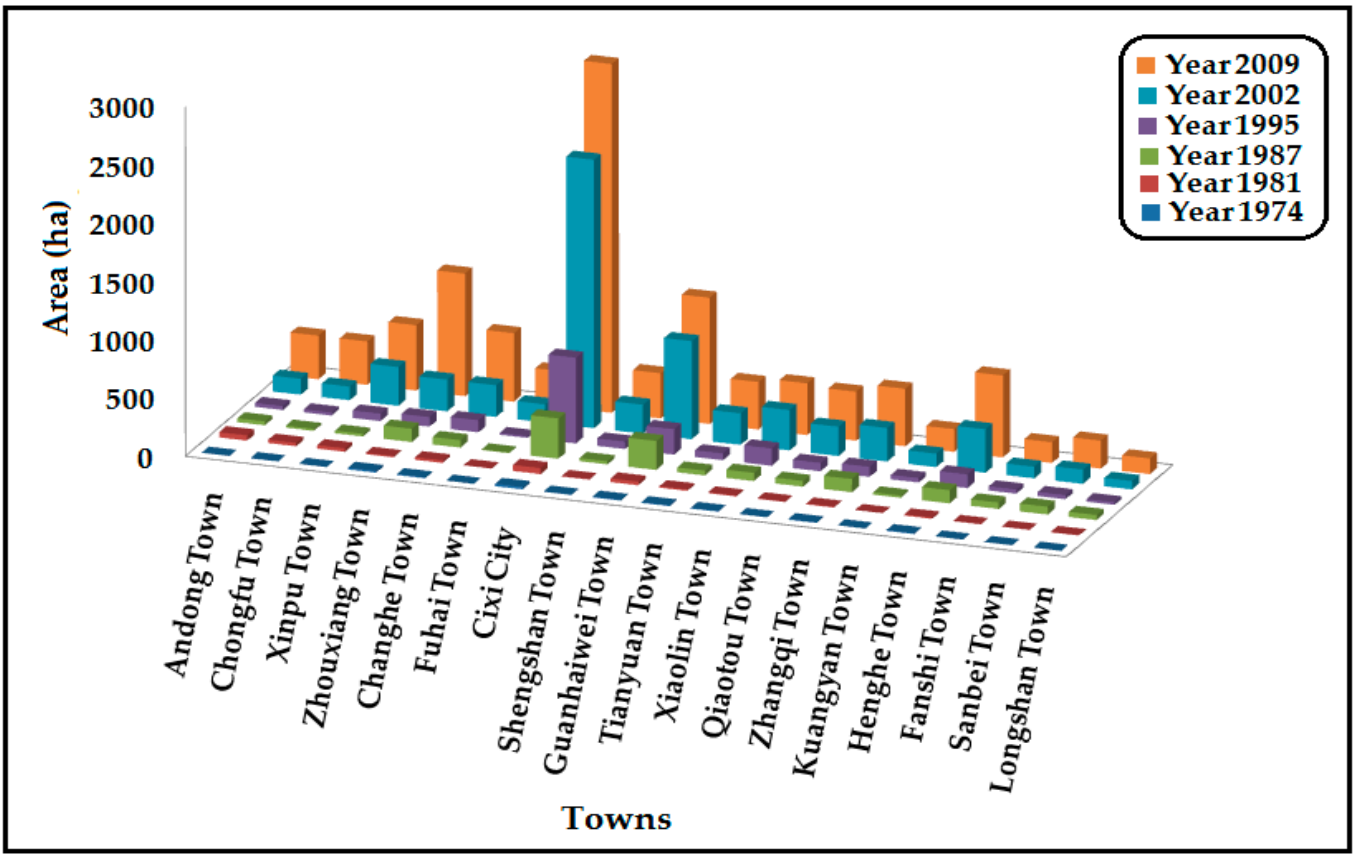

Figure 8. Area of impervious surface expansion in major towns of Cixi County (1974-2009). 


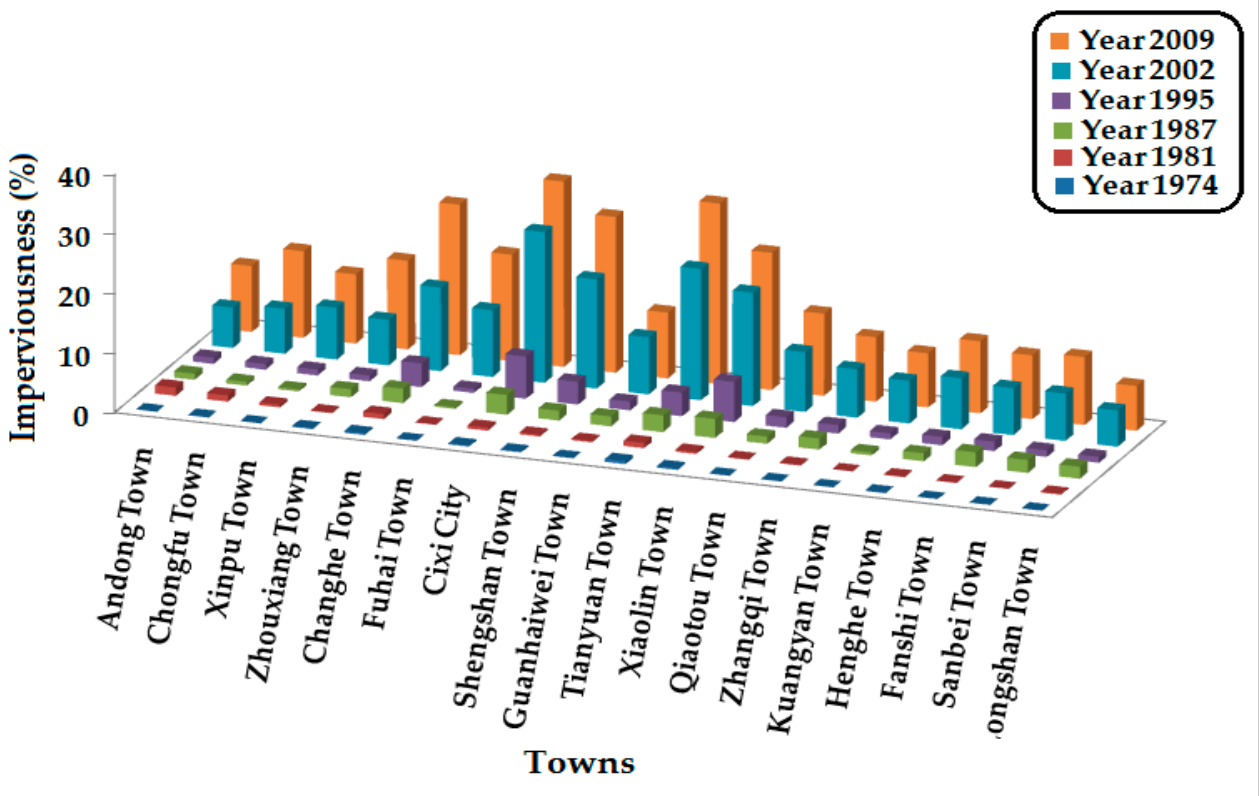

Figure 9. Time series of imperviousness (\%) of major towns in Cixi County (1974-2009).

Moreover, the amount and area of impervious surfaces were calculated merely for rural regions of Cixi County. In 1974, the area of impervious surfaces in rural regions was only 1.19 ha, while it increased to 1247.27 ha in 2009 (Figure 10a). Additionally, the imperviousness (\%) changed from $0.126 \%$ in 1974 to $23.055 \%$ in 2009 (Figure 10b).

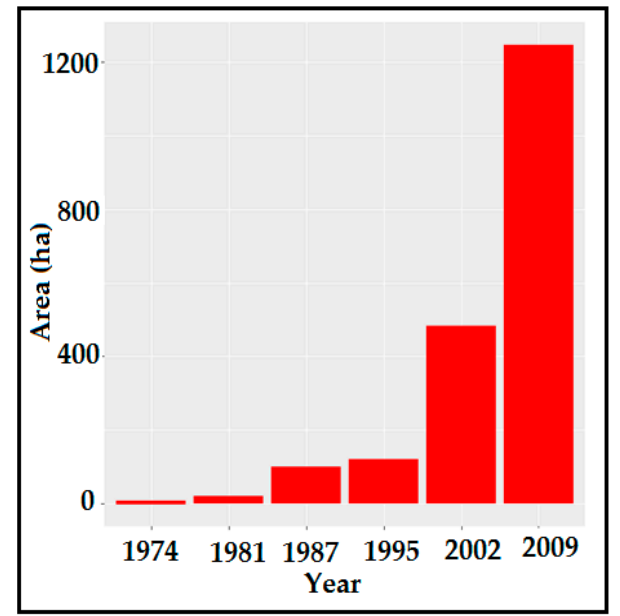

(a)

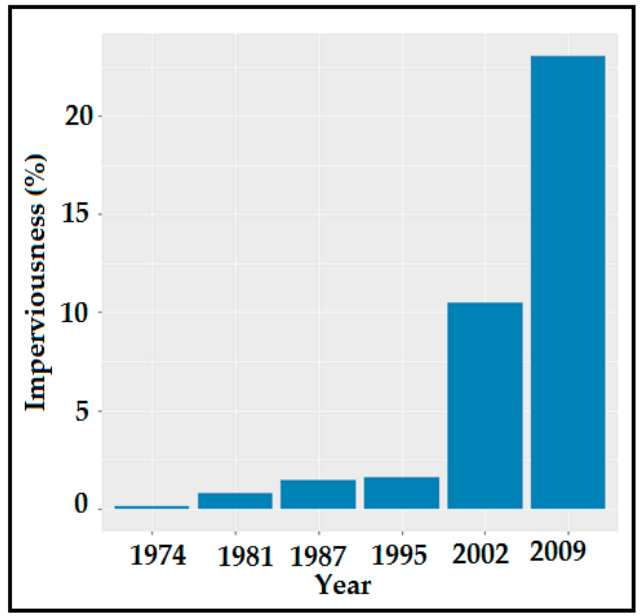

(b)

Figure 10. (a) Area of rural development (1974-2009); (b) imperviousness (\%) of rural regions in Cixi County (1974-2009).

\subsection{Landscape Metrics}

The growth of impervious surfaces was also analyzed using spatial metrics. Cixi County witnessed diffusion, as evidenced by increasing the number of patches (NP) from 487 in 1974 to 5974 in 1987 (Figure 11). After 1987, NP declined to 3478, which suggested a coalescence stage. Accordingly, the results reflected that one cycle of diffusion and coalescence was completed between 1974 and 2002. 
However, impervious surfaces coalesced into saturated impervious surfaces between 2002 and 2009 . Moreover, patch density (PD) increased between 1974 and 1987 (diffusion) but decreased between 1987 and 2002 (coalescence). Filling open spaces can be mirrored in decreasing Euclidean mean nearest neighbor distance (ENN_MN) during the whole study period. It is worth mentioning that ENN_MN between individual impervious surface patches had high a value, which suggested the initial stages of diffusion (1974-1987).

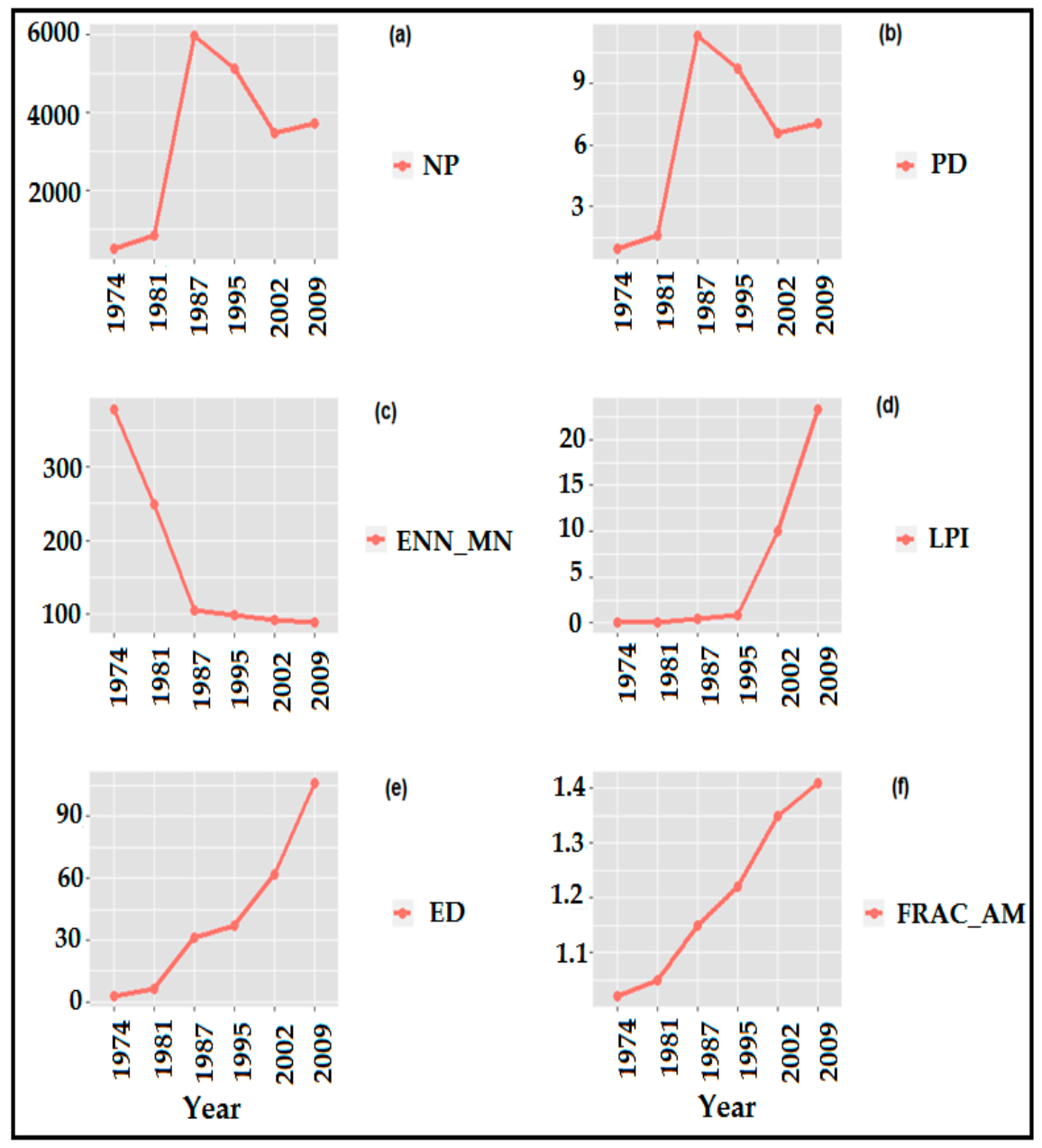

Figure 11. Temporal impervious surface growth signatures of spatial metrics: (a) number of patches (NP), (b) patch density (PD), (c) Euclidean mean nearest neighbor distance (ENN_MN), (d) largest patch index (LPI), (e) edge density (ED), and (f) area weighted mean patch fractal dimension (FRAC_AM).

Edge density (ED), largest patch index (LPI), and area weighted mean patch fractal dimension (FRAC_AM) did not show fluctuating patterns, but they experienced sharp increases overtime. In Cixi County, increasing fragmentation due to the diffusion and coalescence stages may give rise to increasing ED. The rise of LPI suggested increasing connection between individual impervious surface patches and urban centers. Additionally, high shape complexity can be mirrored in FRAC_AM, which was greater than one for all years.

\subsection{Simulation}

The SLEUTH model generated two outcomes: Calibrated results for each year (1974, 1981, 1987, 1995, 2002, and 2009) (Figure 12a) and predicted results for 2015 (Figure 12b). In terms of areas of urban regions, results showed that there was not a considerable difference between the simulated one 
by SLEUTH and that estimated by the impervious surface technique (Figure 12a). The correlation between these two parameters was 0.97 .

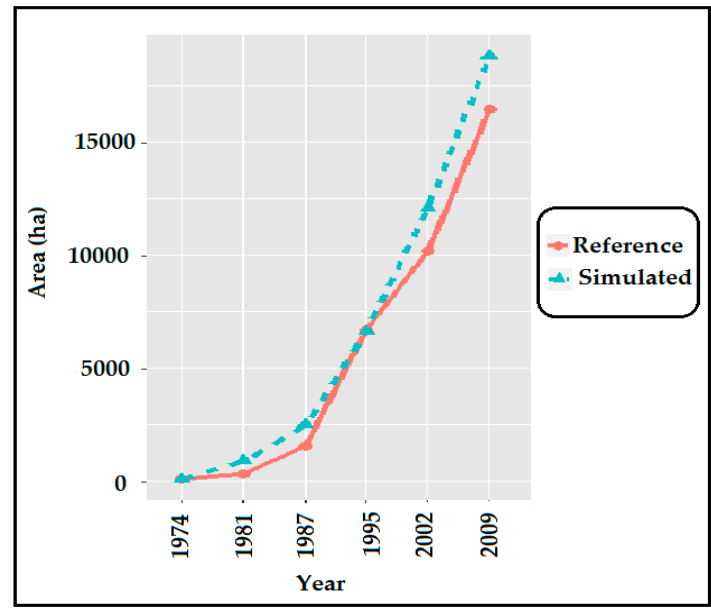

(a)

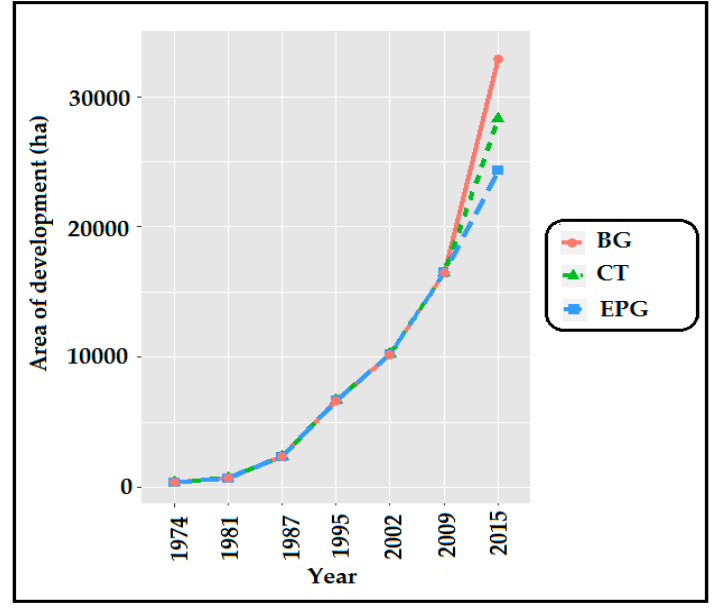

(b)

Figure 12. (a) SLEUTH calibration between 1974 and 2009; (b) predicted area of urban development under three scenarios: CT, EPG, and BG (2009-2015).

The result indicated the Cixi County witnessed urban expansion under all policy scenarios yet, with distinct rates. Under scenarios BG and $\mathrm{CT}$, urban regions experienced rapid development compared to EPG (Figure 12b). The urban area increased by 16,372.76 and 11,787.5 ha under the BG and CT scenarios in 2015, respectively. However, the urban area expanded only by 7828 ha under the EPG scenario in 2015.

As shown in Figure 13, urban development occurred along transportation corridors as well as outside and inside of existing urban regions under CT, BG, and EPG. For example, urbanization tended to infill open space based on the EPG scenario, as evidenced in the probability values, $65-100 \%$ (Figure 13). By contrast, the BG and CT scenarios introduced outward growth, such as the conversion of agricultural lands into impervious surfaces.

Impervious surface growth occurred along new highways, especially those linked to the Hangzhou Bay Bridge [13]; for example, Shenhai Expressway (Hangzhou Bridge Highway) in the North and East of the county, Zhongheng line in the South, and Zhangxi North highway in the West of the county. Moreover, the North East and East of Cixi County were susceptible to impervious surface growth, partly because these areas consisted of more vacant and flat lands in comparison to the Northwest and South of this county, which have been under land conservation programs.

The rural boundary of Cixi County in 2009 was overlaid on the probability map of SLEUTH under the CT, BG, EPG, and CPPR scenarios in 2015. Most rural lands were affected by rapid impervious surface growth based on EPG, CT, and BG (Figure 14). However, CPPR led to urban development; for example, impervious surface regions could shrink to 2275 ha in 2015. 

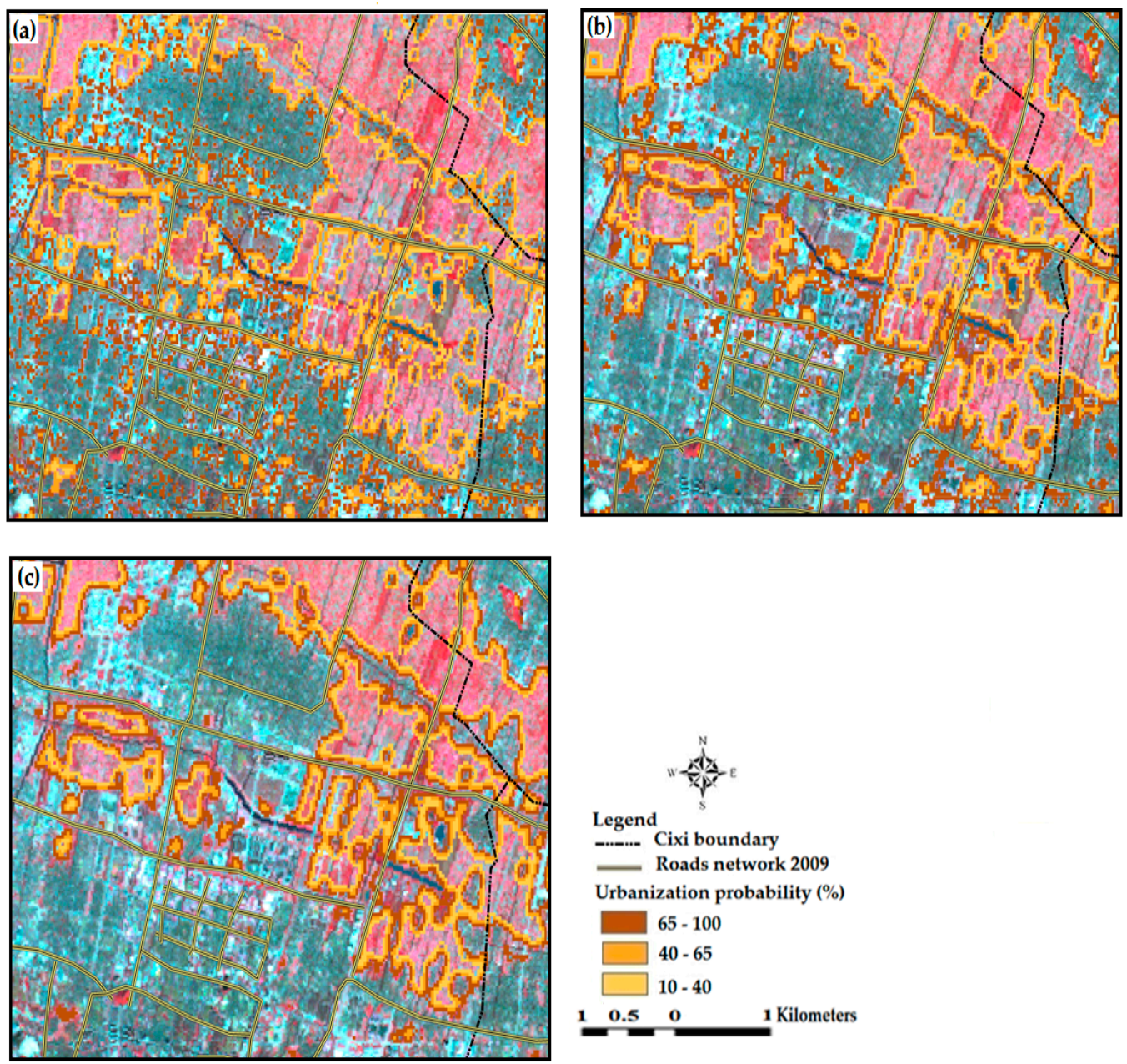

Figure 13. A comparison among different scenarios: (a) EPG, (b) CT, and (c) BG. The background is aLandsat TM color composite image (Near Infrared, Red, Green bands) in 2009. The location is the center of Cixi city $\left(30^{\circ} 12^{\prime} 35.114^{\prime \prime} \mathrm{N}\right.$ and $\left.121^{\circ} 15^{\prime} 26.143^{\prime \prime} \mathrm{E}\right)$.

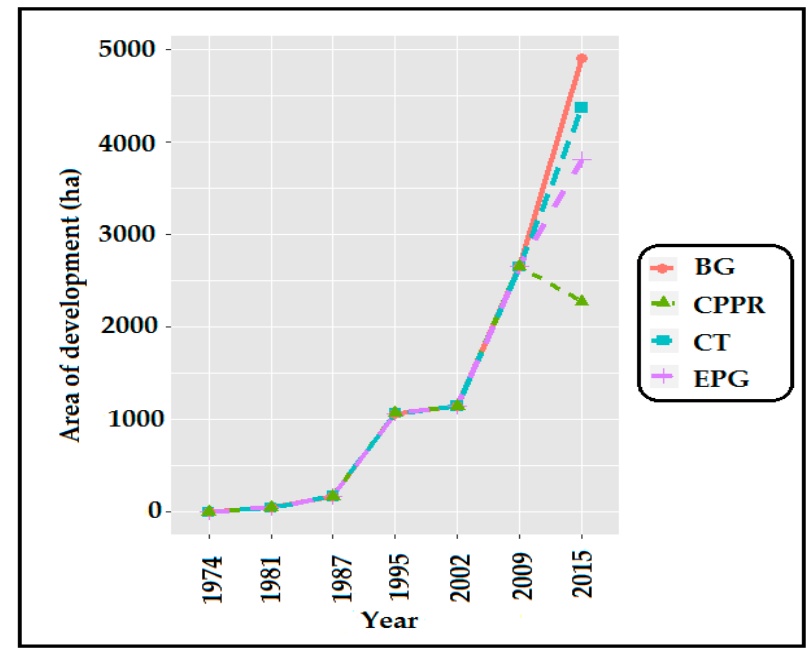

Figure 14. Rural development under four scenarios: CT, EPG, BG, CPPR in 2015.

The probability map indicated that impervious surface development in rural areas occurred in the edge of existing built-up areas and rural regions based on BG and CT, whereas the EPG scenario 
led to infilling of open spaces within existing rural regions (Figure 15). Implementation of the CPPR scenario was likely to transfer impervious surface development from rural areas to around major cities; therefore, this policy could preserve rural landscapes.
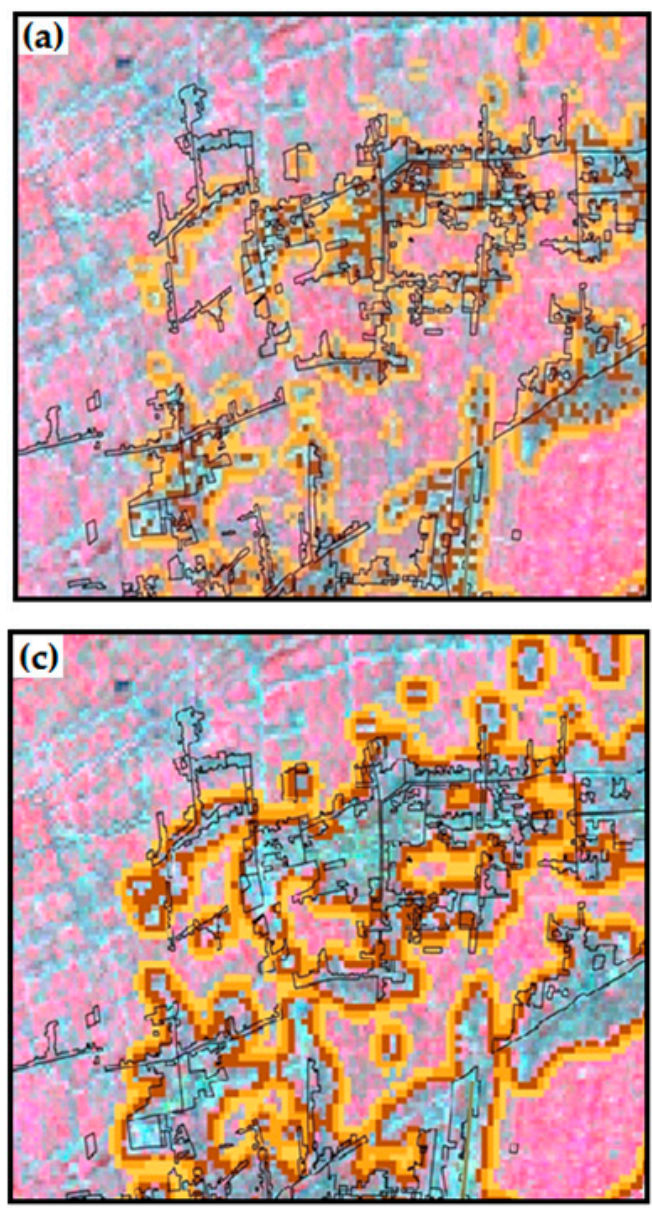

Urbanization probability (\%)

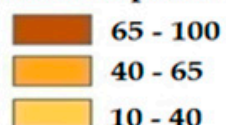

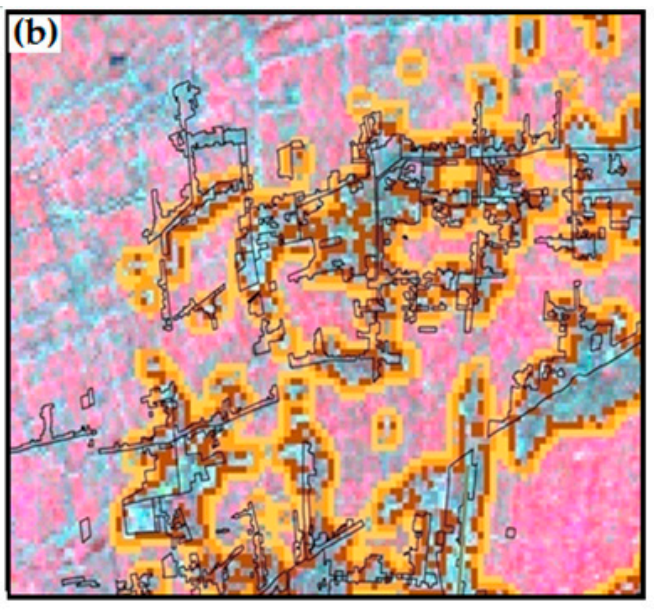
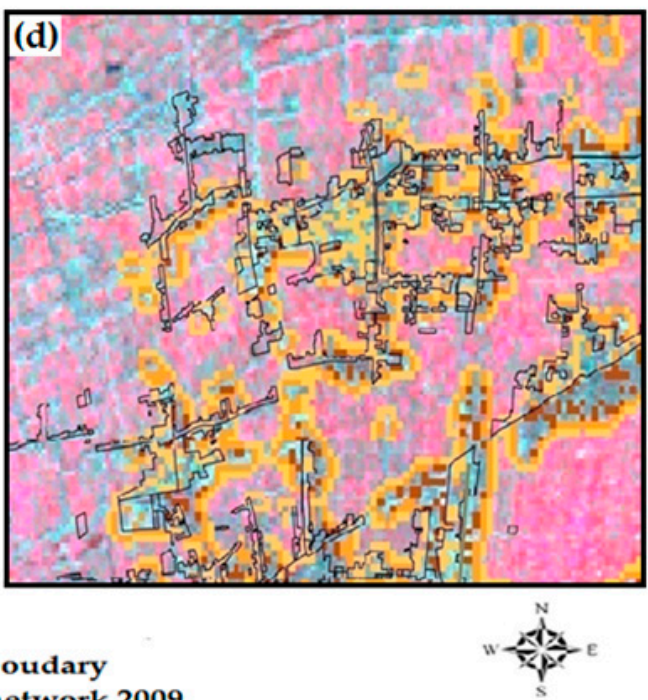

Rural boudary

Roads network 2009

I Kilometers

Figure 15. Urban development in rural regions according to the four different scenarios: (a) EPG, (b) CT, (c) BG, and (d) CPPR. The background is a Landsat TM color composite image (Near Infrared, Red, and Green bands) in 2009. The coordinates of this area are $\left(30^{\circ} 15^{\prime} 8.676^{\prime \prime} \mathrm{N}\right.$ and $\left.121^{\circ} 7^{\prime} 30.418^{\prime \prime} \mathrm{E}\right)$.

\section{Discussion}

For the sake of succinct explanation, the discussion is restricted to the research questions presented in the introduction:

\section{Q1. How can we establish a reliable multifaceted approach to analyzing the change in impervious surfaces?}

There are both potentials and limitations of the multifaceted approach developed for investigating growth of impervious surfaces, particularly in the context of spatial planning decisions. Precisely monitoring the interaction between the growth of impervious surfaces and spatial planning decisions is an overarching aim for land management applications so as to help control land development in a sustainable manner. Up until recently, substantial efforts for change detection of impervious surfaces were made [9]. Despite the valuable findings, such studies analyzed impervious surfaces from one perspective (e.g., change in impervious surface [37]), thus presenting an unclear picture of 
impervious surface dynamics. This is in conjunction with previous research on the interaction between impervious surface growth and the urban planning activities, which suggested that we must not only quantify change in impervious surfaces, but also discover the rationale behind impervious surface distribution [14,16,38-40].

Compared with the previous studies, analyzing growth of impervious surfaces through the multifaceted approach proposed in this study offers useful information on such growth. Notably: (1) RGB_IS has provided a way to visualize growth of impervious surfaces; (2) the anomaly technique quantifies new development and intensification of impervious surfaces; (3) statistical analysis has measured area and percentage (\%) of impervious surface growth; (4) mechanisms of impervious surface growth are captured by means of landscape metrics; and (5) the SLEUTH model is an efficient tool for simulating growth of impervious surfaces.

The additional information on the dynamics of impervious surface growth may assist in inferring the mechanisms involved in urban development. For instance, the Getis_Ord (Gi) (Figure 6) declined over time. It is likely that high-density impervious surfaces, such as old urban regions, have been transformed into modern urban structures, such as high-rise buildings, during an intensification process. Analyzing RGB_IS, anomaly map, statistical analysis, and landscape metrics at the same time suggests that impervious surfaces' growth has generated compact growth. In addition, the simulation results depict a comprehensive representation of the interactions between impervious surface growth and spatial planning scenarios. Hence, the proposed multifaceted approach has the potential for giving unique insights into the mechanisms of interaction of impervious surfaces and spatial planning decisions.

Despite the advantages, care must be taken when using this framework or similar techniques for analyzing change in impervious surfaces in the context of spatial planning decisions. First, Landsat satellite sensors (Multispectral Scanner (MSS), Thematic Mapper (TM), Enhanced Thematic Mapper Plus (ETM+)) have medium spatial resolution relative to the fine scale of impervious surface structures; therefore, these sensors may give rise to under- and over-estimation of impervious surfaces at the sub-pixel level [41]. Second, time series of impervious surface fractions were converted into categorical levels through a thresholding process in order to employ those images in landscape metrics and SLEUTH. Although the threshold value was selected carefully, its potential for introducing uncertainty should be considered. Third, the SLEUTH model simulates only new development, and it cannot predict intensification, as demonstrated in its guidelines. Despite these limitations, investigation based on the proposed multifaceted method can systematically and comprehensively present the process of impervious surface growth.

\section{Q2. How do spatial planning decisions impact the distribution of impervious surfaces' growth?}

Our findings indicated that the growth of impervious surfaces occurred through two mechanisms: Expansion and intensification, as observed with RGB-IS, landscape metrics, and anomaly mapping. The urban peripheries, villages, and areas along transportation corridors witnessed expansion of impervious surfaces. This change could be explained through spatial planning decisions on developing transportation corridors and new urban development. In terms of transportation corridors, Cixi County has implemented comprehensive and modern transportation projects in order to support urban and industrial developments, though such projects could promote growth of impervious surfaces [13]. Our change detection results indicated a substantial increase of impervious surfaces along the transportation corridors (Figures 5a, 6a and 7). Moreover, close visual inspection using Google Earth images confirmed that Cixi County experienced not only the construction of highway networks, but also the expansion of impervious surfaces along these networks (Figure 16). Indeed, spatial development decisions on transportation corridors may lead to new urban and economic development [42].

The results revealed the expansion of impervious surfaces in urban peripheries and rural regions of Cixi County. This pattern was consistent with the spatial development decisions of Cixi County for urban planning. In fact, the geographical location of Cixi County (i.e., close to three mega-cities: 
Ningbo, Hangzhou, and Shanghai, and near deep water) may promote a range of land development policies. This finding was confirmed by Cixi County's spatial planning decisions for the period 2002-2020, which projected substantial growth of impervious surfaces through new built-up and industrial zones [43].

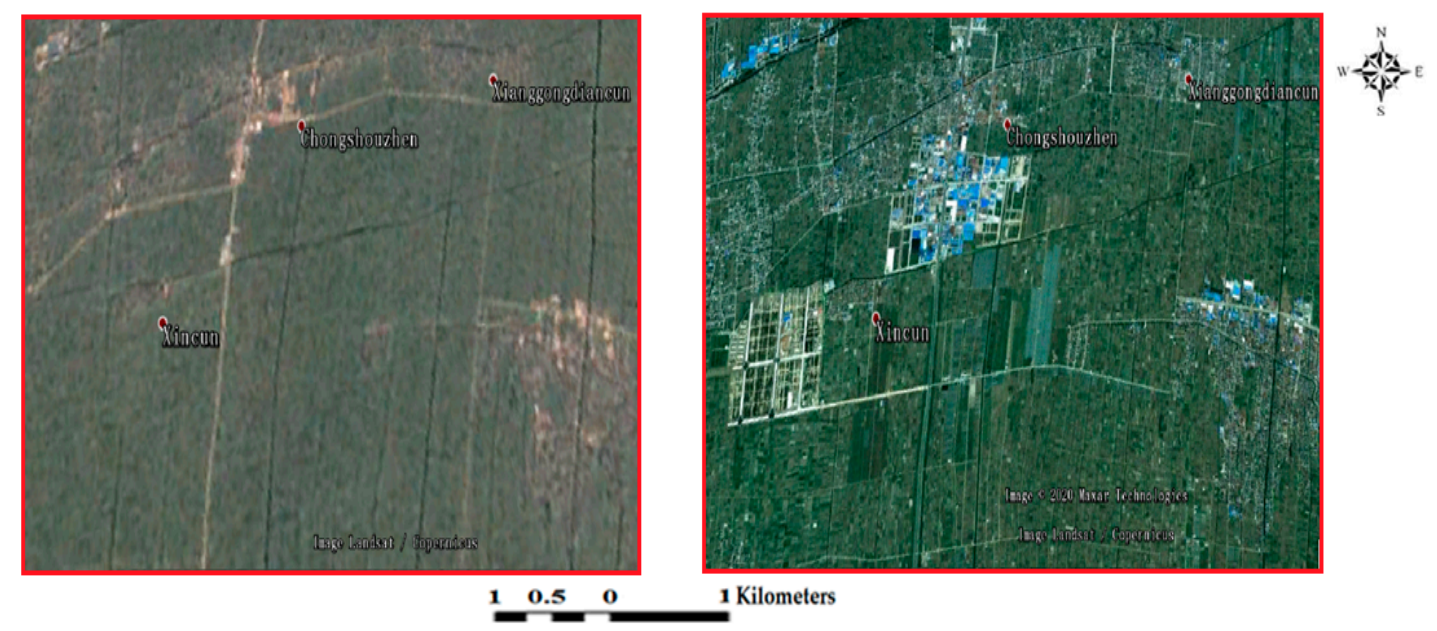

(a)

(b)

Figure 16. Growth of impervious surfaces along transportation corridors and edges of the existing Towns (a) Google Earth ${ }^{\mathrm{TM}} 2000$, and (b) Google Earth ${ }^{\mathrm{TM}}$ 2009. The coordinates of this area are $\left(30^{\circ} 15^{\prime} 50.20^{\prime \prime} \mathrm{N}\right.$ and $\left.121^{\circ} 16^{\prime} 54.79^{\prime \prime} \mathrm{E}\right)$.

With respect to intensification, RGB_IS and the anomaly map highlighted change in impervious surfaces within existing urban regions. Intensification of impervious surfaces could be linked to spatial re-development regulations that target renovation of old-style urban structures. In terms of Cixi County, several intensification policies have been implemented in order to enhance the city's status, i.e., to show a modern urban image (Figure 17). This result was consistent with Han's findings that many small coastal cities in China experienced rapid intensification, which is characterized by tall buildings and wide streets [44].

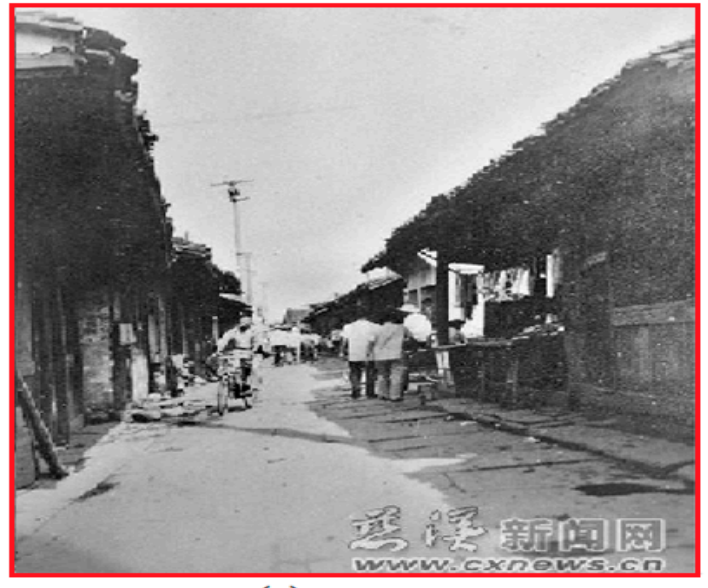

(a)

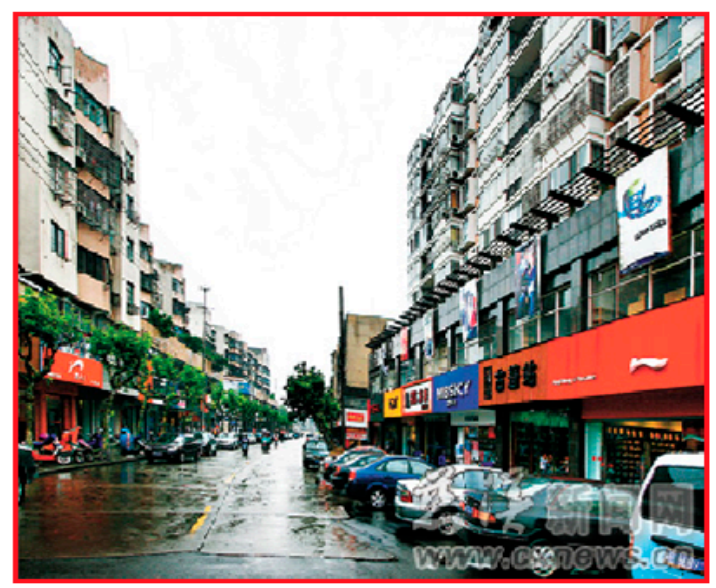

(b)

Figure 17. Internal modifications of impervious surfaces; location: Dong Meng street, Cixi city in (a) 1971 and (b) 2008 (https://ieba.baidu.com/p/3670490200). 
Putting expansion and intensification of impervious surfaces together, it can be observed that the impervious surface development in Cixi County has become compact, as shown in the landscape metrics, imperviousness index (\%), and visual interpretation. The compact growth was generated through filling of open space between towns, thus forming a large, continuous impervious surface region. It is becoming evident that the aforementioned spatial planning decisions may be only one of the factors triggering substantial growth of impervious surfaces in such forms.

\section{Q3. Is simulated impervious surface growth consistent with reality?}

The results from the county-level investigation have provided an overall perspective of urban growth under four scenarios in the future of Cixi County. The findings in the BG, CT, EPG, and CPPR scenarios indicated that urbanization would mainly go towards compactness as a result of infilling of open spaces in side urban regions (Figure 18-red rectangle). Our investigation confirmed the finding of Bahhat et al. [45] that cities in developing countries are becoming more compact in spite of the beginnings of decentralization. In addition, the findings of this research were consistent with previous research based on SLEUTH in other countries. For example, Xi et al. pointed out that most of the new development in the future, particularly on the basis of the current scenario, would be the result of infilling of vacant land between urban regions [46]. Furthermore, the BG and CT scenarios indicated that urban areas developed outward from the existing urban regions along with the infilling of open space between urban patches (Figure 18a,b—red rectangle).

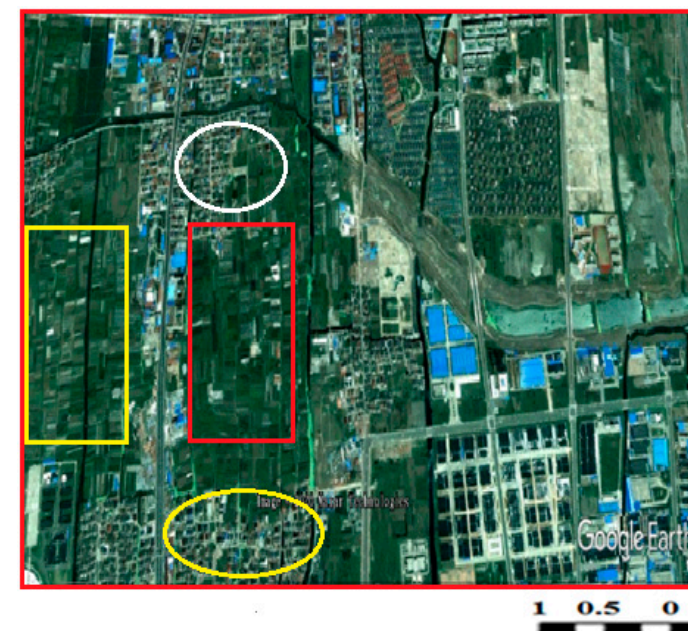

(a)

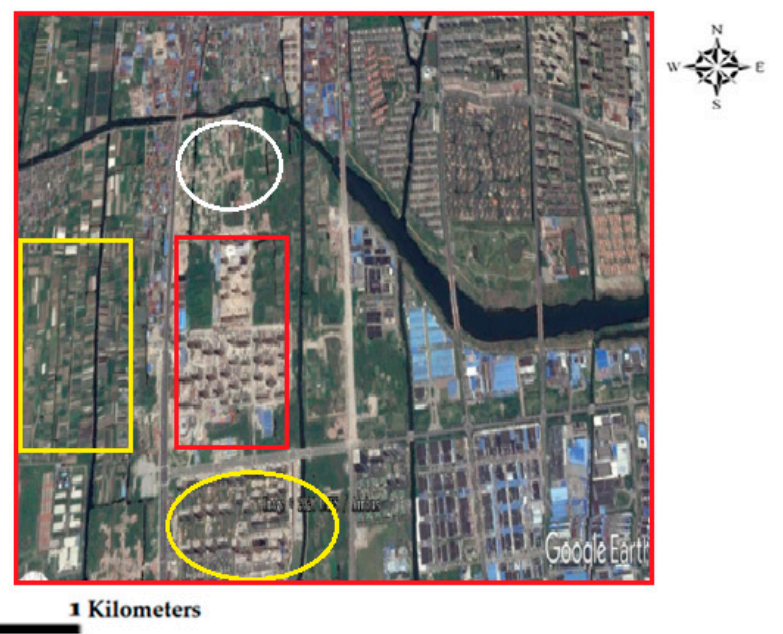

(b)

Figure 18. Predicted impervious surface growth: Land transition around rural area (yellow ellipse), compact growth (red square), shirking rural impervious surfaces (white circle); (a) Google Earth ${ }^{\mathrm{TM}}$ 2002, (b) Google Earth ${ }^{\mathrm{TM}} 2014$. The coordinates of this area are $\left(30^{\circ} 13^{\prime} 04.69^{\prime \prime} \mathrm{N}\right.$ and $\left.121^{\circ} 16^{\prime} 07.85^{\prime \prime} \mathrm{E}\right)$.

Another issue in this research is rural development. The forecast results showed that rural land development increased sharply under the BG, CT, and even EPG scenarios. The rural development was a consequence of continuous suburban expansion around urban regions and land transition within rural areas (Figure 18a,b-yellow ellipse). A number of studies demonstrated that the growth of smaller towns in rural areas, suburbanization, transportation, and rural industrialization were the most important factors for rural developments in China [47-49]. However, many vacant lands around rural lands were preserved under the CPPR scenario (Figure 18a,b-yellow rectangle). This was due to the transition of old urban structures within rural regions into new ones (intensification), as evidenced in Figure 18 (yellow ellipse and white circle). 


\section{Recommendations}

An important question that arises from the findings of this study is related to the future of the interaction between impervious surface growth and spatial planning decisions. Research on impervious surfaces, regardless of the sensors, classification, and change detection, seems to be widely accepted and established through time. Using data from current archives of satellite sensors (e.g., Landat OLI, Sentinel missions, and WorldView-3) can also elaborate more details for accurate mapping of impervious surfaces and their changes.

Despite valuable findings, significant gaps exist in impervious surface studies. A critical aspect of the gap observed in such studies is not limited only to the understanding of the interaction between impervious surfaces growth and spatial planning decisions, but also to the scrutinizing of the behavior of these surfaces. From this perspective, it can be argued that there is a need to develop multifaceted approaches for analyzing the growth of impervious surfaces from different angles. In addition, the results of such investigations should be considered as potential solutions for sustainable land use development. Therefore, we identify three major suggestions for future research:

(1) From a scientific perspective, more research is needed to integrate mapping, change detection, and simulation into one framework so as to comprehensively understand change in impervious surfaces and implement appropriate spatial decisions.

(2) Future studies should combine integrations of simulation and change detection along with former spatial planning decisions into an analytical processing system (e.g., machine learning and Artificial Intelligence(AI)) in order to implement sustainable spatial planning decisions smartly for future growth of impervious surfaces (Figure 19).

(3) Studies combining the aspects of spatial planning decisions, impervious surface development, and general regional development (like economy and demographics) could contribute to more knowledge-based planning decisions.

(4) A fruitful communication between impervious surface scientists and those from other disciplines, such as land management, urban geography, public health, remote sensing, and hydrology, can lead to innovative solutions for monitoring and protecting both urban and natural ecosystems.

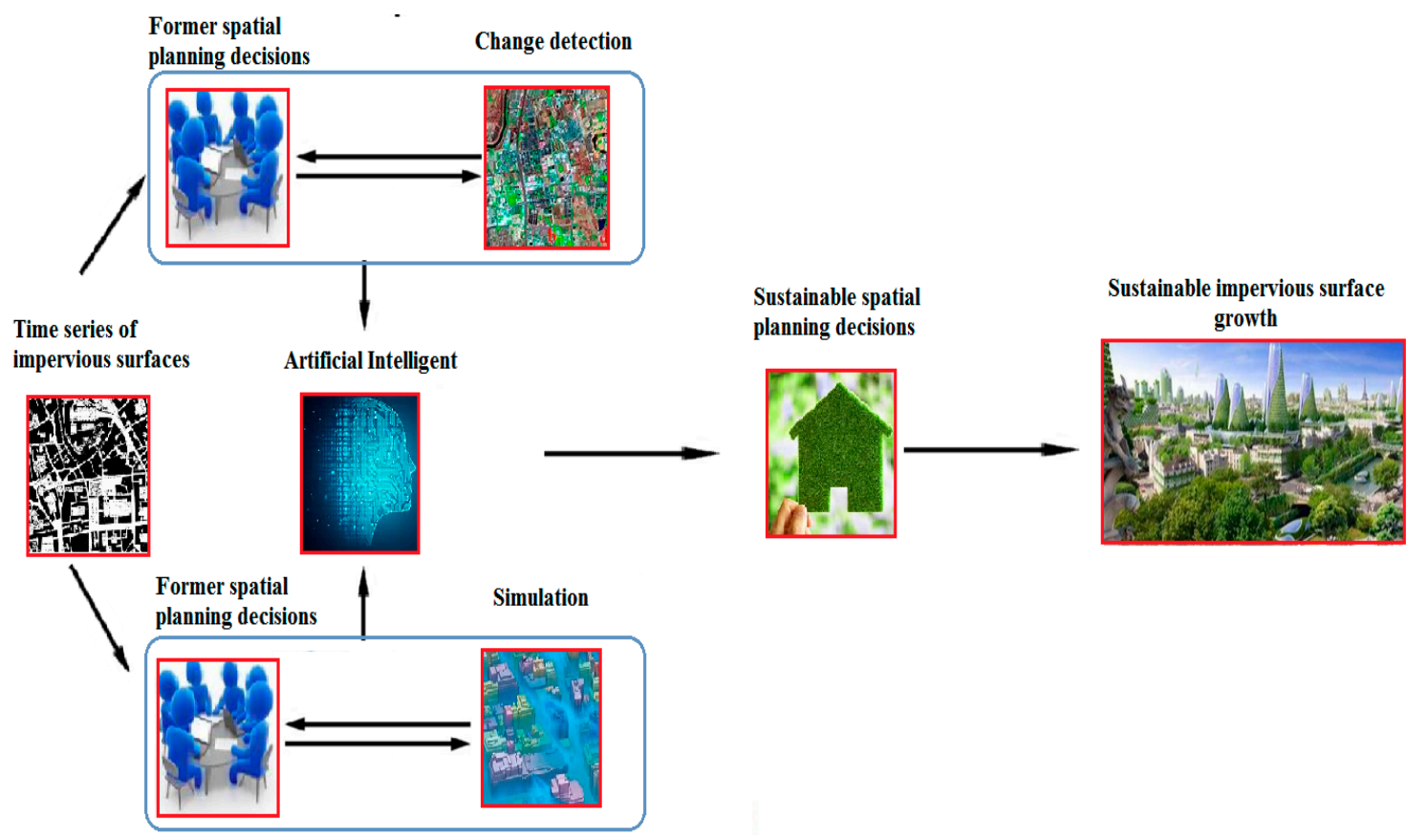

Figure 19. Potential analytical system for sustainable spatial planning decisions in the context of impervious surface growth. 


\section{Conclusions}

This paper developed a multifaceted approach with three components: Visualization, numerical analysis, and simulation at the sub-pixel level to comprehensively understand growth of impervious surfaces for the years of 1974, 1981, 1987, 1995, 2000, 2002, and 2009. Our findings showed that Cixi County has experienced tremendous impervious surface growth, in which the impermeable lands amounted to $16,494.75$ ha in 2009, more than 40 times that in 1974 .

Moreover, the SLEUTH model was employed to simulate impervious surface growth in Cixi County between 2009 and 2015. It was found that urban areas will grow in the edges of existing urban regions if the BG and CT scenarios are adopted for Cixi County. In contrast, the results from the EPG and CPPR scenarios showed that much more land could be preserved in the county.

The proposed multifaceted approach in this case study offers a new perspective for analyzing growth of impervious surfaces. Such a framework is valuable for understanding the dynamics of impervious surface growth and informing regions that are currently undergoing rapid growth.

Supplementary Materials: The following are available online at http://www.mdpi.com/2071-1050/12/10/4109/s1, Figure S1: Feature space, Figure S2: Spectral analysis, Figure S3: Spectral library viewer; Figure S4: Representative endmembers library, Figure S5: High spatial resolution imagery, Figure S6: Cixi Counry spatial development planning for 2002-2020, Table S1: Estimation of MESMA accumulated fractions and panchromatic estimates, Table S2: Summary indices for reference and modeled fractions, Table S3: Accuracy assessment.

Author Contributions: G.A.A. reviewing the paper; J.W. provided scientific review; A.R.S. conceived, designed, processed, analyzed, and wrote the manuscript; K.W. provided scientific directions. All authors have read and agree to the published version of the manuscript.

Funding: This research is funded by the National Natural Science Foundation of China (4197236).

Acknowledgments: We offer our sincere thanks to Rui Gao from the School of International Studies of Zhejiang University for her valuable English editing. We also offer our sincere thanks to Yunhong Yang from the Environment Department of Zhejiang Province for graphical editing. The authors thank the Editor and anonymous reviewers for their constructive comments, suggestions, and help in enhancing the manuscript.

Conflicts of Interest: The authors declare no conflict of interest.

\section{References}

1. Jilge, M.; Heiden, U.; Neumann, C.; Feilhauer, H. Gradients in urban material composition: A new concept to map cities with spaceborne imaging spectroscopy data. Remote Sens. Environ. 2019, 223, 179-193. [CrossRef]

2. Ma, Y.X.; Wright, J.; Gopal, S.; Phillips, N. Seeing the invisible: From imagined to virtual urban landscapes. Cities 2020, 98, 102559. [CrossRef]

3. Hua, L.Z.; Zhang, X.X.; Nie, Q.; Sun, F.Q.; Tang, L.N. The Impacts of the Expansion of Urban Impervious Surfaces on Urban Heat Islands in a Coastal City in China. Sustainability 2020, 12, 475. [CrossRef]

4. Souza, F.L.; Valente-Neto, F.; Severo-Neto, F.; Bueno, B.; Ochoa-Quintero, J.M.; Laps, R.R.; Bolzan, F.; Roque, F.D. Impervious surface and heterogeneity are opposite drivers to maintain bird richness in a Cerrado city. Landsc. Urban Plan. 2019, 192, 103643. [CrossRef]

5. Peroni, F.; Pristeri, G.; Codato, D.; Pappalardo, S.E.; De Marchi, M. Biotope Area Factor: An Ecological Urban Index to Geovisualize Soil Sealing in Padua, Italy. Sustainability 2020, 12, 150. [CrossRef]

6. Yao, L.; Wei, W.; Chen, L.D. How does imperviousness impact the urban rainfall-runoff process under various storm cases? Ecol. Indic. 2016, 60, 893-905. [CrossRef]

7. Lee, C.; Kim, K.; Lee, H. GIS based optimal impervious surface map generation using various spatial data for urban nonpoint source management. J. Environ. Manag. 2018, 206, 587-601. [CrossRef]

8. Huang, J.M.; Chang, H.Y.; Wang, Y.S. Spatiotemporal Changes in the Built Environment Characteristics and Urban Heat Island Effect in a Medium-Sized City, Chiayi City, Taiwan. Sustainability 2020, 12, 365. [CrossRef]

9. Gong, P.; Li, X.C.; Zhang, W. 40-Year (1978-2017) human settlement changes in China reflected by impervious surfaces from satellite remote sensing. Sci. Bull. 2019, 64, 756-763. [CrossRef]

10. Han, Y.; Jia, H.F. Simulating the spatial dynamics of urban growth with an integrated modeling approach: A case study of Foshan, China. Ecol. Model. 2017, 353, 107-116. [CrossRef] 
11. Lichtblau, E.; Oswald, C.J. Classification of impervious land-use features using object-based image analysis and data fusion. Comput. Environ. Urban 2019, 75, 103-116. [CrossRef]

12. Puertas, O.L.; Henriquez, C.; Meza, F.J. Assessing spatial dynamics of urban growth using an integrated land use model. Application in Santiago Metropolitan Area, 2010-2045. Land Use Policy 2014, 38, 415-425. [CrossRef]

13. Shahtahmassebi, A.R.; Wu, C.; Blackburn, G.A.; Zheng, Q.; Huang, L.Y.; Shortridge, A.; Shahtahmassebi, G.; Jiang, R.W.; He, S.; Wang, K.; et al. How do modern transportation projects impact on development of impervious surfaces via new urban area and urban intensification? Evidence from Hangzhou Bay Bridge, China. Land Use Policy 2018, 77, 479-497. [CrossRef]

14. Weng, Q.H. Remote sensing of impervious surfaces in the urban areas: Requirements, methods, and trends. Remote Sens. Environ. 2012, 117, 34-49. [CrossRef]

15. Stone, B. Paving over paradise: How land use regulations promote residential imperviousness. Landsc. Urban Plan. 2004, 69, 101-113. [CrossRef]

16. Michishita, R.; Jiang, Z.B.; Xu, B. Monitoring two decades of urbanization in the Poyang Lake area, China through spectral unmixing. Remote Sens. Environ. 2012, 117, 3-18. [CrossRef]

17. Shahtahmassebi, A.; Pan, Y.; Lin, L.; Shortridge, A.; Wang, K.; Wu, J.X.; Wu, D.; Zhang, J. Implications of land use policy on impervious surface cover change in Cixi County, Zhejiang Province, China. Cities 2014, 39, 21-36. [CrossRef]

18. Chen, X.L.; Jia, X.P.; Pickering, M. A Nighttime Lights Adjusted Impervious Surface Index (NAISI) with Integration of Landsat Imagery and Nighttime Lights Data from International Space Station. Int. J. Appl. Earth. Obs. 2019, 83, 101889. [CrossRef]

19. Ou, J.P.; Liu, X.P.; Liu, P.H.; Liu, X.J. Evaluation of Luojia 1-01 nighttime light imagery for impervious surface detection: A comparison with NPP-VIIRS nighttime light data. Int. J. Appl. Earth Obs. 2019, 81, 1-12. [CrossRef]

20. Zhang, L.; Weng, Q.H.; Shao, Z.F. An evaluation of monthly impervious surface dynamics by fusing Landsat and MODIS time series in the Pearl River Delta, China, from 2000 to 2015. Remote Sens. Environ. 2017, 201, 99-114. [CrossRef]

21. Liu, C.; Zhang, Q.; Luo, H.; Qi, S.H.; Tao, S.Q.; Xu, H.Z.Y.; Yao, Y. An efficient approach to capture continuous impervious surface dynamics using spatial-temporal rules and dense Landsat time series stacks. Remote Sens. Environ. 2019, 229, 114-132. [CrossRef]

22. Shahtahmassebi, A.R. Dynamics of Impervious Surface pattern in Cixi County and Its Simulation. Ph.D. Thesis, Zhejiang University, Hangzhou, China, 2011.

23. Jensen, J. Introductory Digital Image Processing; Science Press and Pearson Education Asia Limited: Beijing, China, 2007.

24. Shahtahmassebi, A.; Yu, Z.L.; Wang, K.; Xu, H.W.; Deng, J.S.; Li, J.D.; Luo, R.S.; Wu, J.; Moore, N. Monitoring rapid urban expansion using a multi-temporal RGB-impervious surface model. J. Zhejiang Univ. Sci. A 2012, 13, 146-158. [CrossRef]

25. Shahtahmassebi, A.R.; Song, J.; Zheng, Q.; Blackburn, G.A.; Wang, K.; Huang, L.Y.; Pan, Y.; Moore, N.; Shahtahmassebi, G.; Haghighi, R.S.; et al. Remote sensing of impervious surface growth: A framework for quantifying urban expansion and re-densification mechanisms. Int. J. Appl. Earth Obs. 2016, 46, 94-112. [CrossRef]

26. McGarigal, K.; Cushman, S.; Neel, M.; Ene, E. FRAGSTATS v3:Spatial Pattern Analysis Program for Categorical Maps; University of Massachusetts: Amherst, MA, USA, 2002.

27. Chaudhuri, G.; Clarke, K.C. Modeling an Indian megalopolis- A case study on adapting SLEUTH urban growth model. Comput. Environ. Urban 2019, 77, 101358. [CrossRef]

28. Clarke, K.C.; Hoppen, S.; Lenard, G. A self-modifying cellular automaton model of historical urbanization in the San Francisco Bay area. Environ. Plan. B Plan. Des. 1997, 24, 247-261. [CrossRef]

29. Al-shalabi, M.; Billa, L.; Pradhan, B.; Mansor, S.; Al-Sharif, A.A.A. Modelling urban growth evolution and land-use changes using GIS based cellular automata and SLEUTH models: The case of Sana'a metropolitan city, Yemen. Environ. Earth Sci. 2013, 70, 425-437. [CrossRef]

30. Kuo, H.F.; Tsou, K.W. Modeling and Simulation of the Future Impacts of Urban Land Use Change on the Natural Environment by SLEUTH and Cluster Analysis. Sustainability 2018, 10, 72. [CrossRef] 
31. Park, S.; Clarke, K.C.; Choi, C.; Kim, J. Simulating Land Use Change in the Seoul Metropolitan Area after Greenbelt Elimination Using the SLEUTH Model. J. Sens. 2017, 2017, 4012929. [CrossRef]

32. Bihamta, N.; Soffianian, A.; Fakheran, S.; Gholamalifard, M. Using the SLEUTH Urban Growth Model to Simulate Future Urban Expansion of the Isfahan Metropolitan Area, Iran. J. Indian Soc. Remote 2015, 43, 407-414. [CrossRef]

33. Sakieh, Y.; Salmanmahiny, A.; Jafarnezhad, J.; Mehri, A.; Kamyab, H.; Galdavi, S. Evaluating the strategy of decentralized urban land-use planning in a developing region. Land Use Policy 2015, 48, 534-551. [CrossRef]

34. Hua, L.Z.; Tang, L.N.; Cui, S.H.; Yin, K. Simulating Urban Growth Using the SLEUTH Model in a Coastal Peri-Urban District in China. Sustainability 2014, 6, 3899-3914. [CrossRef]

35. Jantz, C.A.; Goetz, S.J.; Shelley, M.K. Using the SLEUTH urban growth model to simulate the impacts of future policy scenarios on urban land use in the Baltimore-Washington metropolitan area. Environ. Plan. B 2004, 31, 251-271. [CrossRef]

36. Lichtenberg, E.; Ding, C.G. Assessing farmland protection policy in China. Land Use Policy 2008, 25, 59-68. [CrossRef]

37. Zhang, P.Y.; Pan, J.J.; Xie, L.T.; Zhou, T.; Bai, H.R.; Zhu, Y.X. Spatial-Temporal Evolution and Regional Differentiation Features of Urbanization in China from 2003 to 2013. ISPRS Int. Geo-Inf. 2019, 8, 31. [CrossRef]

38. Powell, R.L.; Roberts, D.A.; Dennison, P.E.; Hess, L.L. Sub-pixel mapping of urban land cover using multiple endmember spectral mixture analysis: Manaus, Brazil. Remote Sens. Environ. 2007, 106, 253-267. [CrossRef]

39. Powell, S.L.; Cohen, W.B.; Yang, Z.; Pierce, J.D.; Alberti, M. Quantification of impervious surface in the Snohomish Water Resources Inventory Area of Western Washington from 1972-2006. Remote Sens. Environ. 2008, 112, 1895-1908. [CrossRef]

40. Rashed, T. Remote sensing of within-class change in urban neighborhood structures. Comput. Environ. Urban 2008, 32, 343-354. [CrossRef]

41. Li, X.C.; Gong, P. An "exclusion-inclusion" framework for extracting human settlements in rapidly developing regions of China from Landsat images. Remote Sens. Environ. 2016, 186, 286-296. [CrossRef]

42. Wang, Z.B.; Xu, G.; Bao, C.; Xu, J.B.; Sun, F.H. Spatial and economic effects of the Bohai Strait Cross-Sea Channel on the transportation accessibility in China. Appl. Geogr. 2017, 83, 86-99. [CrossRef]

43. Zheng, Q.; He, S.; Huang, L.Y.; Zheng, X.Y.; Pan, Y.; Shahtahmassebi, A.R.; Shen, Z.Q.; Yu, Z.L.; Wang, K. Assessing the Impacts of Chinese Sustainable Ground Transportation on the Dynamics of Urban Growth: A Case Study of the Hangzhou Bay Bridge. Sustainability 2016, 8, 666. [CrossRef]

44. Han, S.S. Urban expansion in contemporary China: What can we learn from a small town? Land Use Policy 2010, 27, 780-787. [CrossRef]

45. Bhatta, B. Analysis of Urban Growth and Sprawl from Remote Sensing Data; Springer: Heidelberg, Germany; New York, NY, USA, 2010; p. 172.

46. Xi, F.M.; Hu, Y.M.; He, H.S.; Wu, X.Q.; Bu, R.C.; Chang, Y.; Liu, M.; Yu, J. Simulate urban growth based on RS, GIS, and SLEUTH model in Shenyang-Fushun metropolitan area northeastern China. In Proceedings of the 2009 Joint Urban Remote Sens. Event, Shanghai, China, 20-22 May 2009; p. 959.

47. Deng, J.S.; Wang, K.; Hong, Y.; Qi, J.G. Spatio-temporal dynamics and evolution of land use change and landscape pattern in response to rapid urbanization. Landsc. Urban Plan. 2009, 92, 187-198. [CrossRef]

48. Lin, G.C.S.; Ho, S.P.S. China's land resources and land-use change: Insights from the 1996 land survey. Land Use Policy 2003, 20, 87-107. [CrossRef]

49. Long, H.L.; Hellig, G.K.; Li, X.B.; Zhang, M. Socio-economic development and land-use change: Analysis of rural housing land transition in the Transect of the Yangtse River, China. Land Use Policy 2007, 24, 141-153. [CrossRef]

(C) 2020 by the authors. Licensee MDPI, Basel, Switzerland. This article is an open access article distributed under the terms and conditions of the Creative Commons Attribution (CC BY) license (http://creativecommons.org/licenses/by/4.0/). 